\title{
PERSPECTIVAS DE UNA REFORMA MIGRATORIA QUE REGULARICE A INDOCUMEN- TADOS MEXICANOS, EN EL CONTEXTO POLÍTICO ACTUAL DE ESTADOS UNIDOS
}

\author{
Prospects for immigration reform to regularize \\ mexican undocumented, in the current political \\ context of the United States
}

Ismael García Castro ${ }^{1}$

Fecha de recepción: 01 de junio de 2016

Fecha de aceptación: 08 de septiembre de 2016 


\section{Resumen}

En 1986, el Congreso estadounidense aprobó la Immigration Reform and Control Act (IRCA), la última reforma que consideró la regularización masiva de indocumentados. La IRCA ha permitido regularizar más de tres millones de personas, la mayoría mexicanos. Casi tres décadas después, todavía doce millones de indocumentados, residen en Norteamérica. ¿Cuáles son actualmente las perspectivas de que las condiciones de esta población mejoren mediante una reforma que les saque de la clandestinidad? El presente artículo busca responder esta interrogante, analizando la situación actual, con base en examinar el contexto histórico, en que se han aplicado las leyes y políticas migratorias estadounidenses.

Palabras clave: Reforma migratoria, Estados Unidos, indocumentados, pragmatismo.

\section{Abstract}

In 1986, the US Congress passed the Immigration Reform and Control Act (IRCA), the last reform which saw the mass regularization of undocumented workers. IRCA has allowed regularize more than three million people, mostly Mexicans. Nearly three decades later, still twelve million undocumented, reside in North America. What are the prospects now that the conditions of this population will improve through a reform that takes them out of hiding? This article seeks to answer this question, analyzing the current situation, based on examining the historical context that have been applied US immigration laws and policies.

Keywords: Immigration reform, United States, undocumented, pragmatism. 


\section{Introducción}

través de su historia, el Estado estadounidense ha respondido con leyes y políticas apa-
rentemente contradictorias y dispersas ante la inmigración, las cuales han tenido como
constante un modelo de pragmatismo, sustentado en acciones, ante determinadas circunstancias políticas y económicas, sin necesidad de fundamentos ideológicos de fondo y, que tienen como base intereses, compromisos y negociaciones de grupos, que en el ejercicio de su hegemonía, aplican o proponen leyes y políticas de beneficios privados que se ofrecen como acciones democráticas del Estado-nación. En otras palabras, un modelo que busca conciliar los intereses de las grandes corporaciones y grupos de interés con los del Estado, o bien, convertir la razón del mercado en razón del Estado. ${ }^{2}$

Con fundamento en este modelo pragmático, la inmigración ha operado como una bisagra que, en tiempos de estabilidad política, auge económico, o en circunstancias como los conflictos bélicos, se abre para reclutar inmigrantes, mientras que, en épocas recesivas o de crisis política, se promueven percepciones negativas hacia los inmigrantes desde el poder $y$, con ello, medidas restrictivas cuyo propósito es limitar los flujos de inmigrantes.

Aquí se analiza el contexto histórico que compara las acciones en materia de formulación y aplicación de leyes y políticas migratorias entre diferentes administraciones federales del poder ejecutivo y legislativo de Estados Unidos. Asimismo, se retoman algunas consideraciones sobre el manejo de la opinión pública, ya que el consenso de la ciudadanía influye en las decisiones que se toman al interior del Congreso y la Casa Blanca, especialmente en un sistema político que promueve la reelección de sus gobernantes.

Se aborda asimismo, el impacto del fenómeno migratorio en el debate político en Estados Unidos en las últimas décadas, particularmente después del 11 de septiembre de 2001. Se analiza, además, la importancia que el tema de la inmigración, particularmente la no autorizada procedente de México, adquirió en las plataformas partidistas y de candidatos a la presidencia en las elecciones de 2008, 2012 y en las actuales de 2016, con el propósito de atraer el voto de los latinos en general y de los electores de origen mexicano en particular, ya que, estos últimos representan dos terceras partes del total de los hispanos en los Estados Unidos.

La tesis central del análisis implica que las instancias de poder de la nación estadounidense, a través de la historia, han endurecido o flexibilizado de manera pragmática (Orozco, 1992, 1996, 2001, 2004, 2010), sus propuestas de leyes y políticas sobre inmigración, con base en el contexto político y económico que atraviese el país, indistintamente de ideologías de partidos o gobernantes, generando que se valore a la inmigración, especialmente la indocumentada, como necesaria e incluso recomendable, en ciertos periodos y coyunturas, así como excesiva y riesgosa, en otros (Muñoz, 2009). Con base en lo anteriormente expuesto, es que sostenemos que el contexto político y económico actual de Estados Unidos, no es favorable a la aprobación de una reforma migratoria amplia e integral y aún menos, que de darse, pudiera favorecer la regularización masiva de inmigrantes indocumentados.

2- En este artículo no pretendemos hacer un análisis del concepto de pragmatismo. Nos remitimos al significado que al término aplica sobre la extensa bibliografía del investigador José Luis Orozco $(1992,1996,2001,2004,2010)$. 


\section{La inmigración en Estados Unidos a través de la historia}

Aun antes de conformarse como nación independiente, Norteamérica ha sido un destino de inmigrantes. Personas de todos los continentes han emigrado hacia este territorio, expulsados por las condiciones de vida de su lugar de origen, o en busca de oportunidades laborales y nuevos horizontes sociales y políticos. En el caso de la población de origen africano, su inmigración fue forzada.

Para satisfacer una demanda creciente de mano de obra, la constitución del nuevo país, reservó el control de la inmigración a la Federación. En 1790, se promulgó la primera ley de naturalización en Estados Unidos. En ella se reservó el derecho a la residencia y posterior ciudadanía a cualquier extranjero que fuera persona blanca y libre, y se garantizó la provisión de mano de obra esclava y de inmigrantes europeos, buscando el equilibrio político entre el norte comercial y el sur de economía agrícola esclavista (Adams, 2013).

Durante la mayor parte de los siglos xIx y xx, los Estados Unidos implementaron una política que incentivó la llegada masiva de inmigrantes. Entre 1815 y 1970, más de 46 millones de personas ingresaron para establecerse en esa nación. Desde 1920, fecha en que inicio el registro de inmigrantes, cerca de 75 millones ingresaron a los Estados Unidos (Martin, 2014:48). Particularmente, en el año de 1907 llegaron más de 1 millón doscientos mil inmigrantes (Adams, 2013:5).

En todo el siglo xIX, el impulso a la inmigración fue un elemento central de la política económica expansionista de Estados Unidos (Mármora, 2002; Hanson, 2009). Particularmente, las últimas décadas del siglo XIX y los primeros años del siglo xx, se caracterizaron por la llegada masiva de mexicanos para trabajar en la agricultura, la minería, los ferrocarriles y la industria pesada. Aun cuando Estados Unidos implementó restricciones para la entrada de cierto tipo de inmigrantes, por ejemplo, la Ley de Exclusión de China de 1882, aprobada por un congreso de mayoría republicana, durante la administración del presidente, también republicano, Chester Arthur (1881-1885). La situación no afectó significativamente a los inmigrantes de origen mexicano, por el contrario, se incentivó su arribo para sustituir a los trabajadores de origen chino (Durand y Massey, 2002; Hackett, 2006; Alarcón, 2011).

Durante esta época, la situación sobre inmigración fue manejada en un doble nivel: el informal, que se regía por las leyes de la oferta y la demanda que imponía el mercado de trabajo; el nivel formal, ya sujeto al Servicio de Inmigración y Naturalización (INS por sus siglas en inglés), creado en 1891 bajo la administración del republicano Benjamin Harrison (1889-1893), como la agencia federal para aplicar las leyes sobre inmigración y, que a partir de entonces, operaría con base en restringir o permitir la entrada de extranjeros, de acuerdo con un complejo equilibrio entre intereses y necesidades del mercado de trabajo en Estados Unidos y de diversas coyunturas políticas y económicas (Jorjani, 2008).

Particularmente, durante los primeros años del siglo $\mathrm{xx}$, la inmigración mexicana se intensificó, ya que tanto empleadores como creadores de las políticas migratorias de ese país, revaloraron las ventajas que ofrecía contratar mexicanos en lugar de europeos. Ante la reducción del número de trabajadores de origen europeo y asiático, la fuerza laboral mexicana fue considerada la ideal, debido a sus singulares características de flexibilidad y temporalidad (Calavita, 1989; Andreas, 2000; Jiménez, 2011). Para abastecer la creciente demanda de mano de obra mexicana, los empleadores estadounidenses recurrieron a los servicios de contratistas, quienes, a través de cierta colaboración de autoridades locales, se internaban 
en México para reclutar trabajadores, principalmente en regiones rurales. Esta práctica, común entre 1900 y 1920, fue conocida como sistema de enganche (Durand, 1994).

En 1917, se adoptó la primera Ley de inmigración que integraba las diversas disposiciones en esta materia y tenía como principal objetivo crear restricciones en ciertas zonas geográficas, prohibiendo la inmigración de la mayoría de los países de Asia y limitando la proveniente de África, Latinoamérica y algunos países de Europa. Asimismo, de personas a quienes se les negaba la entrada por razones de salud, o ideología política o religiosa. Después de que el Congreso aprobara esa legislación, el Departamento del Trabajo, encargado de su administración, buscó la manera de establecer excepciones para admitir temporalmente como trabajadores no inmigrantes a miles de mexicanos, ya que la Primera Guerra Mundial produjo escasez de mano de obra (Durand, 1994, 2007).

A partir de que Estados Unidos se vio envuelto en el conflicto bélico mundial, más de un millón de sus ciudadanos fueron enrolados en las fuerzas armadas, por lo que diversas áreas de la economía, particularmente en el sector agrícola, empezaron a sufrir la escasez de mano de obra. El gobierno del demócrata Woodrow Wilson (1812-1920), elaboró un programa especial de trabajadores inmigrantes, al que se le denominó Programa de Importación Temporal de Mano de Obra Mexicana (Narváez, 2006). Emigrar al Norte fue una oportunidad que no dejaron pasar más de 216000 mexicanos que se establecieron en Estados Unidos entre 1910 y 1920 (Laborde, 2011; Mendoza y Tapia, 2011).

\section{Alternancia de periodos de inmigración a gran escala y de portaciones masivas}

El fin de la Primera Guerra Mundial provocó que el Gobierno de Estados Unidos redirigiera sus esfuerzos por controlar el flujo de inmigrantes, particularmente el de mexicanos, iniciándose así, una política que consistió en alternar periodos de inmigración a gran escala con deportaciones masivas (Mercado y Piña, 2010; Durand, 2013). El auge inicial de la primera posguerra llegaba a su fin para el verano de 1920. El panorama para la inmigración mexicana se modificó radicalmente, y si bien no se restringió formalmente la entrada de mexicanos, sí se deportó a miles de ellos (Durand, 1994; Morales, 1989; Laborde, 2011).

Debido a que en 1921 entraron a Estados Unidos más de 700000 inmigrantes, de origen europeo en su mayoría, el Congreso estadounidense aprobó la Emergency Quota Act, legislación que fue conocida como la Ley de Cupos. Sancionada por el republicano Warren Harding (1921-1923), el objetivo principal de esta legislación era limitar el número de inmigrantes que llegaba anualmente. La ley operaba mediante la

imposición de cuotas con base en un porcentaje de inmigración, de acuerdo al país de origen de quienes solicitaban ingreso. El Congreso de Estados Unidos, mayoritariamente republicano, estipuló que la inmigración europea no debía exceder el 3\% de la población inmigrante del mismo origen que ya se encontrara en el país, lo que correspondía a 356000 personas para ese año (1921). La Ley de Cupos de 1921 cumplió efectivamente el objetivo de disminuir la inmigración europea hacia 1924, cuando sus cuotas disminuyeron hasta menos de la mitad de las que operaron durante el periodo de 1905 a 1914 (Rodríguez, 2009).

En mayo de 1924, bajo la administración del sucesor de Harding, el también republicano Calvin Coolidge (1923-1929), y con un Congreso mayoritariamente republicano, se aprobó una nueva ley de inmi- 
gración, más estricta con respecto a las cuotas por país y región, la National Origins Act, la cual pretendía limitar aún más, la entrada de inmigrantes de Asia, África y algunos países europeos como Italia, Polonia y Rusia (Manges, 2008). La nueva ley establecía un límite de ingreso de ciento cincuenta mil inmigrantes por año (Morales, 1989: 88; Laborde, 2011).

No fue sorpresa que las severas leyes de 1921 y 1924, hacia la inmigración regular, hayan tenido como consecuencia incrementar la inmigración indocumentada, particularmente la proveniente del sur, que incluyó población procedente de Europa, que utilizaba esta vía para evitar las leyes de cuotas o cupos. Ante el incremento de la inmigración indocumentada, el Gobierno estadounidense respondió con la creación de la Patrulla Fronteriza en 1924 (Morales, 1989; Durand, 2007; Serrano, 2010).

Con el advenimiento de la Gran Depresión, al finalizar la década de los veinte, los niveles de desempleo se dispararon. De cuatro millones de desocupados que había en enero de 1930, para la primavera de 1931 aumentó a ocho millones. Para 1933, más de quince millones de personas en Estados Unidos se encontraban sin trabajo (Morales, 1989; Rude, 2009). La crisis afectó incluso a quienes habían podido conservar su empleo, ya que los salarios y las horas de trabajo también se redujeron. Indudablemente, esta situación constituía el pretexto perfecto para responsabilizar a los inmigrantes de los problemas económicos y el desempleo (Durand, 2007). Pronto se produjeron reacciones xenofóbicas a nivel local. En Arizona, por ejemplo, se emitió una ley que establecía que al menos el 80\% de los empleados, en cualquier ramo, debían ser ciudadanos estadounidenses. En 1931, en California, se promulgó otra legislación que prohibía a las empresas emplear a inmigrantes en obras financiadas con recursos públicos. La Ley de Trabajadores Extranjeros de California desplazó a los mexicanos de empleos como la construcción de carreteras, escuelas y edificios de gobierno (Massey et al., 2002).

No obstante, la gravedad de las reacciones xenofóbicas locales y el grueso de las expulsiones de inmigrantes mexicanos correspondió a las acciones del Gobierno Federal. Durante los años de la Depresión, se calcula que en Estados Unidos había más de un millón de indocumentados mexicanos (Bustamante, 1997). Tanto los inmigrantes con estatus legal como irregular, estuvieron sujetos a ser deportados o regresar, al perder sus empleos (Alarcón, 2011). Se estima que, entre 1929 y 1935, cerca de medio millón de mexicanos regresaron a su país debido a la deportación o pérdida del empleo (Pesce, 2008: 7).

Con el inicio de la Segunda Guerra Mundial, la movilización de la industria para cubrir las necesidades de guerra y el reclutamiento militar provocó, de nuevo, escasez de mano de obra en Estados Unidos, por lo que las deportaciones masivas concluyeron y el flujo migratorio proveniente del Sur se reactivó (Massey et al., 2002; Durand, 2007). Para 1942, tan solo los agricultores de California reclamaban la falta de más de treinta mil trabajadores para levantar las cosechas (Morales, 1989: 144). En ese mismo año, se firmaría el primer convenio de braceros entre México y Estados Unidos (Massey, 2008). La firma del acuerdo fue considerada como una contribución de México al conflicto bélico. El presidente Franklin Roosevelt (1933-1945), lo describió como: "un elocuente testimonio del importante papel que juega México en la batalla para la producción de alimentos, de la que depende el inevitable éxito de nuestro programa militar" (Morales, 1989: 147).

Una vez finalizado el conflicto mundial, los principales beneficiarios del Programa Bracero, los grandes agricultores de California y Texas, encontraron nuevas razones para extender el esquema. A pesar de la extensión del programa, el número de braceros contratados no fue suficiente para cubrir la demanda que la economía de posguerra, en pleno auge, estaba requiriendo, por lo que los empleadores empezaron 
a utilizar medidas ajenas al acuerdo para abastecerse, por propia cuenta, de mano de obra extranjera, haciendo correr la voz entre los braceros de que había empleos suficientes para quienes decidieran ingresar al país (Narváez, 2006). Ante esta situación, el gobierno del demócrata Harry S. Truman (1945-1952), implementó, desde 1949, la política de drying out, la cual establecía la legalización de los indocumentados o wetbacks (espaldas mojadas), como fueron llamados peyorativamente los inmigrantes mexicanos irregulares, cuyo mote también se usó en México desde entonces para designarlos como mojados. Esta política fue una importante concesión a los empresarios agrícolas, quienes se beneficiaron con la depreciación de los salarios, ocasionada por la sobreoferta de mano de obra (Mercado y Palmerin, 2009). Tan solo en 1950, serían regularizados 96239 indocumentados bajo los términos del drying out, mientras que solo fueron contratados 19813 nuevos braceros (Morales, 1989: 175).

Para el inicio de la década de los cincuenta, los intereses en contra del Programa Bracero parecían darle fin, sin embargo, con el inicio de la Guerra de Corea, los empresarios agrícolas estadounidenses lograron ligar, una vez más, su dependencia de mano de obra mexicana a las necesidades de su país en guerra. En respuesta a las presiones de los agricultores, en 1951 se aprobó, por un congreso de mayoría demócrata, la Ley Pública 78, que estableció las bases de extensión del programa de braceros por los siguientes 14 años (Esquivel, 2009; Alarcón, 2011).

En 1952, el Congreso de Estados Unidos emitió el Acta de Inmigración y Nacionalidad (INA por sus siglas en inglés), también conocida como McCarran-Walter Act, que fue el primer estatuto integral sobre asuntos migratorios en Estados Unidos. La nueva legislación establecía, en un principio, que albergar, transportar y encubrir a indocumentados era ilegal. Sin embargo, en ese mismo año, se aprobaría una enmienda propuesta al Congreso por la Delegación Texana, conocida como Texas Proviso, la cual declaraba que otorgar empleo a un indocumentado no significaba proporcionarle albergue (Durand, 1994; Calavita, 1989; Pinedo, 2009). Evidentemente, esta enmienda dejaba desprovisto todo el espíritu de la Ley McCarran-Walter (Alarcón, 2011).

Una vez terminada la Guerra de Corea, la urgencia de disponer de mano de obra inmigrante volvió a regir la política migratoria pragmática, por lo que la administración del republicano Dwight Eisenhower (1953-1960), puso a operar la maquinaria de deportaciones masivas, a través de la que fue conocida como Operación Wetback, para regresar a México a más de un millón de indocumentados. La extensión del Programa Bracero y la paralela implementación y difusión de las operaciones de deportación masiva, satisfacían (a excepción de los deportados y sus familias) a todos los interesados en el tema: empresarios agrícolas, políticos locales, la opinión pública estadounidense y, particularmente, a los grupos nativistas (Durand, 2007; Massey et al., 2002; Albertí, 2012).

El pragmatismo con el que se implementó la Operación Wetback, en un periodo de pleno crecimiento de la economía, fue con el fin de aparentar que se controlaba el flujo de indocumentados y, al mismo tiempo, de asegurar el abastecimiento de trabajadores. Durante estos años, la Patrulla Fronteriza jugó un doble papel: de expulsor y de reclutador de inmigrantes. Los indocumentados o wetbacks, como les llamaban despectivamente, eran interceptados por los agentes de la Patrulla Fronteriza, quienes los escoltaban a la frontera con México y, una vez ahí, buscaban llevarlos de regreso, ya "legalmente", como parte del Programa de Braceros. En muchos de los casos, eran los agentes de la Patrulla Fronteriza quienes fungían como enganchadores, trasladando a los inmigrantes hasta los centros de trabajo al interior de Estados Unidos (Andreas, 2000). 
Entre 1951 y 1960, casi 300000 mexicanos obtuvieron residencia permanente en los Estados Unidos (Alarcón, 2011: 198), siendo esto clara muestra de que el verdadero objetivo de la Operación Wetback, y de los conductores de la política migratoria norteamericana, era en realidad controlar los flujos, pero garantizando una provisión de mano de obra inmigrante. Los inmigrantes serían bienvenidos únicamente cuando y donde esta fuerza laboral se requiriera, e ingresaran, además, bajo los mecanismos establecidos para ello (Durand, 2007; Alarcón, 2011).

Al final de la década de los cincuenta, la Ley Pública 78, la última enmienda al Programa Bracero, se había mantenido casi intacta y nadie pensaba que podía llegar a su fin, incluso para muchos, el programa de importación de braceros mexicanos se convertiría en la medida oficial y permanente que utilizaría el sector agrícola estadounidense (Durand, 2007). Sin embargo, a principios de los sesenta, las coaliciones liberales del trabajo presionaron al Congreso norteamericano, dominado entonces por los demócratas, y lograron que, en 1961, se estableciera una nueva ley que requería que los empleadores ofrecieran a los trabajadores locales los mismos salarios, jornadas y condiciones físicas con las que contaban los inmigrantes, así como abstenerse de contratar braceros hasta por un año (Fullerton y Barraza, 2009). Con base en la situación antes descrita, la administración del demócrata J.F. Kennedy (1961-1963), empezó a reconsiderar la existencia del Programa Bracero al suponerlo una desventaja, ya que no existía una situación de emergencia que ameritara enfrentarse a distintas fuerzas políticas, en particular las de las coaliciones laborales. De esta forma, el número de braceros en Estados Unidos se redujo en 1962 (Morales, 1989; Verea, 2003). Y en 1964, bajo la presidencia del también demócrata Lyndon Johnson (1963-1968), el Gobierno declaró expirado el Programa Bracero (Chang, 2010).

\section{Intensificación de la migración irregular y aprobación de la
IRCA}

De acuerdo a Hollifield, Martin y Orrenius (2014), las décadas posteriores a la Segunda Guerra Mundial, se caracterizaron por lo que estos autores llamaron la "Paradoja Liberal", es decir el reconocimiento de derechos políticos a las minorías étnicas y los inmigrantes, derivado de la lucha por los derechos civiles. Por otra parte, conforme avanzaba la década de los sesenta, Estados Unidos adquirió un ambiente de certidumbre al interior de la mayoría de los hogares, gracias al incremento de los niveles de vida. Debido a que la economía no representaba el principal problema de la nación, la sociedad estadounidense viró su atención hacia la autoridad moral, cuestionada por la prolongada y desgastante Guerra de Vietnam (Massey, 2008). Bajo esta atmósfera, las políticas que restringían la entrada de migrantes, de acuerdo al origen, fueron contempladas como intolerablemente racistas.

Los grupos promotores de los derechos civiles presionaron al Congreso estadounidense (dominado por los demócratas durante toda la década), para que modificara estas leyes migratorias revocando el sistema de cuotas. Así, en 1965, se promulgó la primera enmienda a la Ley McCarran-Walter o Ley Nacional de Inmigración de 1952. Esta nueva ley, que se conoció como Hart Celler Act, tuvo entre sus principales objetivos dar preferencia a la reunificación familiar, aunque impuso un límite de 120000 visas a inmigrantes del Hemisferio Occidental, lo que afectó particularmente a la inmigración proveniente de México (Hollifield et al., 2008). 
A partir de la segunda mitad de los setenta, Estados Unidos comenzó a experimentar una recesión económica caracterizada por altos índices de inflación y desempleo, así como una caída considerable de los salarios. Desde esta perspectiva, el tema de los indocumentados volvió a convertirse en un problema político nacional. Las aprehensiones a indocumentados, por parte del INs, empezaron a aumentar y se desarrollaron operativos similares al Wetback, con campañas agresivas en los medios, donde el Gobierno intentaba presentar el problema de la inmigración indocumentada como una crisis nacional (Castles y Vezolli, 2009: 70). Como resultado de esto, en 1976, el Gobierno estadounidense disminuyó en un 40\% la emisión de visas a mexicanos.

Para finales de los setenta, y principios de los ochenta, la economía de Estados Unidos alcanzó una severa contracción económica. Este periodo coincide con los últimos años de la presidencia del demócrata James Carter (1977-1980) y el inicio del gobierno del republicano Ronald Reagan (1981-1988). Ambas administraciones protagonizaron una era en la que el escenario político hacia la inmigración, al igual que con muchos otros temas, se volvió profundamente conservador. Bajo argumentos como la supuesta pérdida del control de las fronteras, el asunto de los indocumentados fue calificado, desde entonces, como un problema de seguridad nacional (Cornelius, 1989; Narváez, 2006; Chang, 2010).

La enorme expansión del Ins durante el periodo de 1978 a 1988, fue una clara evidencia del sentido de urgencia que se le dio al problema de la inmigración indocumentada en esos años. El Congreso de Estados Unidos multiplicó el presupuesto del INs en un 185\%, con lo que pasó de \$283.1 millones de dólares en 1978 a $\$ 807.8$ millones en 1988. De igual forma, el número de personal autorizado para esta agencia federal se incrementó en un 53\%, en el mismo periodo, pasando de 10071 a 15453 empleados (Dunn, 1996: 35).

Con la llegada a la Casa Blanca del líder del movimiento neoconservador el ambiente en contra de la inmigración indocumentada se recrudeció. A mediados de 1981, Reagan puso a consideración del Congreso un proyecto que intentaba regularizar la estadía temporal de aquellos indocumentados que demostraran haber ingresado al país antes de 1980 y duplicar, asimismo, de veinte mil a cuarenta mil, las visas anuales para residentes legales, además de implementar un programa de trabajadores huéspedes. La otra cara de la moneda era incrementar sustantivamente los recursos para incrementar la vigilancia en la frontera y aumentar el número de deportaciones.

Los debates en el Congreso sobre una nueva reforma migratoria, culminaron en 1986 con la aprobación de la Ley de Control y Reforma de la Inmigración (IRCA por sus siglas en inglés), que sería la última legislación aprobada por el Congreso de Estados Unidos en materia de regularización masiva de población indocumentada. Esta ley permitió que, en poco más de una década, cerca de dos millones y medio de inmigrantes, mayoritariamente mexicanos, que residían sobre todo en California, Texas e Illinois, pudieran normalizar su estatus y pasar a ser residentes legales. ${ }^{3}$ Con el tiempo una gran cantidad de ellos se convertirían en ciudadanos estadounidenses (Massey y Sana, 2003; García, 2007).

La IRCA, significo un arreglo conveniente entre los interesados en mantener su provisión de mano de obra extranjera barata y quienes abogaban por restringir la entrada de inmigrantes, pues la nueva

3- Bajo la Immigration Reform and Control Act (IRCA) de 1986, dos grupos de inmigrantes indocumentados fueron elegibles para amnistía o regularización. Los extranjeros que hubieran estado residiendo sin documentos en los Estados Unidos desde antes del 1 de enero de 1982, quienes fueron legalizados bajo la sección 245A de la Ley de Inmigración y Nacionalidad (INA). Y los trabajadores agrícolas que hubieran laborado al menos 90 días en el año anterior a mayo de 1986 (Programa Especial para Trabajadores Agrícolas (sAw por sus siglas en inglés), quienes fueron legalizados bajo la sección 210A de la INA. Este último grupo estaba constituido básicamente por mexicanos (Rytina, 2002). 
legislación tuvo como propósito reforzar el control policiaco en las fronteras para dificultar el paso de la inmigración no autorizada, al tiempo que garantizaba, mediante una amnistía, un suministro de trabajadores inmigrantes a la economía estadounidense, particularmente al sector agrícola (Rytina, 2002; Martin, 2014).

Los autores de la IRCA argumentaron que el suministro de trabajadores recientemente regularizados, saturaría la demanda doméstica de trabajadores inmigrantes, mientras que las sanciones a empleadores lograrían detener la contratación de inmigrantes sin documentos. Con esta combinación se esperaba disminuir sustancialmente la entrada de futuros flujos migratorios. No obstante, en la práctica, la nueva ley no tuvo los efectos esperados (Hamann et al., 2008). Paradójicamente, los grandes beneficiados de las sanciones a empleadores, previstas por la IRCA, fueron los propios patrones, ya que las sanciones incrementaron el temor de ser deportados en los indocumentados, lo cual los imposibilitó a defender sus derechos.

Otro factor que cambió las condiciones de los efectos previsibles de la legislación migratoria de 1986, fueron las modificaciones en la estructura económica, particularmente reflejadas en los mercados de trabajo en Norteamérica. Bajo la política económica de corte militarista de la administración de Reagan, Estados Unidos empezó a tener un considerable crecimiento económico, producido por el enorme gasto del sector público. El modelo económico estadounidense también cambió debido al agotamiento de la producción industrial fordista, ${ }^{4}$ que empleaba obreros sindicalizados de altos niveles salariales, por ejemplo, la industria automotriz, la cual se trasladó al exterior. Mientras que los servicios y la manufactura ligera, como las industrias de ensamblaje de electrónicos, computadoras u otras, como la elaboración de muebles o ropa, que se caracterizan por emplear mano de obra inmigrante de baja calificación y salarios, tuvieron un sostenido crecimiento (García, 2003). De esta forma, la reestructuración económica de los ochenta produjo millones de trabajos no especializados que demandaron trabajadores inmigrantes.

El rápido crecimiento de la industria de servicios y manufactura ligera dispersó la mano de obra mexicana, tanto legal como indocumentada, dentro de la economía estadounidense (Cornelius, 1989; Narváez, 2006). Particularmente, los mexicanos empezaron a dejar las zonas rurales para establecerse en las ciudades, obteniendo empleos en hoteles, restaurantes, jardinería, servicios de lavandería, aseo de casas y cuidado de niños, ventas, mantenimiento y construcción, entre otros. Estos trabajos no especializados, receptores de salarios bajos, a los cuales los trabajadores domésticos no estaban dispuestos a someterse, constituyeron la principal oferta laboral de los inmigrantes durante los ochenta (García, 2003).

4- Por fordismo se entiende el sistema de producción y consumo masivo, inaugurado a través del sistema de producción en serie que nació en Estados Unidos a principios del siglo xx, sobre todo con la industria automotriz de Ford, y los estudios sobre la eficiencia del trabajo de Taylor de finales del siglo xix. Esto, aunado al keynesianismo de los treinta, que fue el modelo de la economía mundial durante décadas. Desde el New Deal de Franklin D. Roosevelt se empezó una política intervencionista del Gobierno Federal Norteamericano, la cual incluía incentivar el consumo masivo, por medio de programas de creación de empleo, préstamos, recorte de impuestos, fuertes inversiones en el sector educativo de nivel superior y la creación de un sistema de bienestar social, de seguro social, pensiones y jubilaciones, apoyándose en consolidados sindicatos de alcance nacional. El desarrollo de la Segunda Guerra Mundial y la consecuente Guerra Fría, mantuvo vigente este sistema de producción y consumo masivo, como fuente de impulso de la economía estadounidense. Este sistema entraría en decadencia en la década de los setenta, entre otras cosas, por la crisis del petróleo de 1973 y la declinación productiva de industrias como la automotriz, por la competencia que significaron Japón y Alemania, generándose una reestructuración económica, particularmente en Estados Unidos que trasladó la producción industrial al exterior y redujo enormemente los empleos sindicalizados (García, 2003). 
Obviamente, la política migratoria implementada por Estados Unidos durante los setenta y ochenta, sirvió para sustituir la entrada legal de inmigrantes por un flujo cada vez mayor de indocumentados. Los mexicanos constituyeron el grupo predominante de esa inmigración. Durante el periodo de 1965 a 1986, hubo 5.7 millones de ingresos, de los cuales más del 80\% fueron indocumentados (Massey et al., 2002: 45).

Durante los noventa, el ambiente político estadounidense se enrareció una vez más en contra de los inmigrantes. La fuerte recesión económica por la que atravesó Estados Unidos durante los primeros cuatro años de esa década, fortaleció una corriente antiinmigrante en el partido republicano, el cual se hizo del control de la Cámara de Representantes y del Senado (González, 2008). En California, bajo la premisa de que la inmigración ilegal era la culpable de muchos de los problemas económicos y políticos del Estado, el gobernador republicano Pete Wilson, quien buscaba la reelección, presentó ante el Congreso del Estado en 1994, la Propuesta 187, que buscaba limitar la responsabilidad fiscal del Gobierno Estatal, en cuanto a los inmigrantes, al restringir servicios sociales, médicos y educativos, así como forzar al Gobierno Federal a asumir estos gastos (García y Griego y Verea 1998; García, 2003; García, 2007). Indudablemente, la Propuesta 187 sirvió a Wilson para ganar simpatía entre los votantes que consideraban que los indocumentados llegaban con el propósito de obtener ventaja de los servicios de bienestar social del Estado. En consecuencia, la campaña republicana de 1994, en California, tuvo implicaciones serias en contra de los inmigrantes, aun cuando finalmente la iniciativa no se ejecutó debido a la decisión de un juez federal.

Como los republicanos de todo el país advirtieron que, en California, la Iniciativa 187 tuvo un gran efecto electoral a su favor, empezaron a realizar propuestas similares a nivel nacional; luego los políticos demócratas conservadores también comenzaron a hacer uso de este tipo de propuestas antiinmigrantes, motivo por el cual llegó un momento en el que fue imposible diferenciar a un partido de otro, en cuanto a pronunciamientos y posición sobre la inmigración indocumentada. El entonces presidente, el demócrata William J. Clinton (1993-2000), dio continuidad a estas mismas ideas, a pesar de haber reconocido las importantes contribuciones de los inmigrantes a la sociedad estadounidense. Sin bien manifestó su oposición a la Propuesta 187, Clinton calificó a su propuesta de control migratorio como: "el plan más agresivo y más amplio para luchar contra la inmigración ilegal que jamás haya producido administración alguna” (García y Griego y Verea, 1998: 113).

El nuevo experimento migratorio de la Casa Blanca se basó en dos estrategias principales. Por un lado, se dispuso un incremento sustancial de los recursos del Servicio de Naturalización e Inmigración, especialmente aquellos dedicados al control de las fronteras. La segunda táctica implementada por el gobierno de Clinton, fue la política conocida como prevención por medio de la persuasión. El objetivo era reformular el modelo de operación de la Patrulla Fronteriza, que por décadas había dirigido sus esfuerzos a expulsar a todo inmigrante irregular que acababa de ingresar al país, o en su caso a los que ya tuvieran tiempo residiendo en el mismo, ahora los esfuerzos se concentrarían en disuadir la inmigración a través de bloquear las principales rutas de cruce fronterizo (Cornelius, 2001; Storrs, 2006).

Con la nueva política, lo que Washington pretendía era que la Patrulla Fronteriza dejara de preocuparse por los indocumentados que ya estaban dentro de la nación, para enfocarse en bloquear el acceso a aquellos que estaban buscando ingresar a Estados Unidos. De esta forma, desde 1993, la Patrulla Fronteriza llevó a cabo distintas operaciones, por ejemplo, en ese mismo año, se realizó en la zona de El Paso, 
Texas, la Operación Bloqueo (Hold-the-Line). En 1994, en el área de San Diego, empezó la Operación Guardián (Gatekeeper). Y, en 1996, la Operación Salvaguarda (Safeguard), se implementó en la frontera de Arizona (Rubio, 2011).

Cuando entró en vigor el TLCAN, a partir de 1994, paradójicamente, mientras las barreras a la libre circulación de capitales y mercancías tendieron a disminuirse, ocurrió lo contrario con la movilidad de la fuerza de trabajo, ya que tan solo dos años después de que el Congreso estadounidense ratificara la puesta en marcha del TLCAN, este mismo recinto legislativo, con mayoría republicana, aprobó, en 1996, nuevas leyes migratorias totalmente contrarias al espíritu integracionista, como lo fue la Ley de Responsabilidad Inmigrante y Reforma a la Inmigración Ilegal (IIRIRA por sus siglas en inglés), ${ }^{5}$ y la Ley de Responsabilidad Personal y Reconciliación de Oportunidades de Trabajo (PRwORA por sus siglas en inglés). ${ }^{6}$ Estas nuevas legislaciones federales fueron más allá de la Propuesta 187 de California, ya que pretendían limitar a los inmigrantes en general, no solo a los indocumentados, el derecho al disfrute de varios servicios públicos. Las medidas afectaban principalmente a los inmigrantes más vulnerables como madres solteras, niños y personas mayores, en virtud de los recortes a la asistencia social y los servicios de salud.

Con la IIRIRA, que entró en vigor en abril de 1997, el congreso de mayoría republicana insistió en que la solución al problema migratorio estaba en el aumento considerable a la erogación de recursos destinados a controlar las fronteras, particularmente la de México, para impedir el paso a la inmigración indocumentada. De esta forma, se aumentaría la cantidad de agentes de la Patrulla Fronteriza, a razón de mil por año, y se podrían incrementar los recursos en innovación tecnológica (García y Griego y Verea, 1998; Kerwin y Yi-Ying, 2009).

El propósito de la IIRIRA consistía en controlar la inmigración irregular y dificultar el acceso a servicios públicos para los inmigrantes en general. Representó un cambio radical en el derecho migratorio estadounidense, sobre todo en lo referente a los derechos humanos de los indocumentados y sus familias (Griego y Griego y Verea, 1998; Lonegan, 2006; Vaira-Lucero et al., 2012).

La IIRIRA eliminó también el procedimiento de audiencias de deportaciones y de exclusión vigente, con lo cual se eliminaron muchos de los derechos individuales de los indocumentados sujetos a deportación. Se estableció un nuevo procedimiento llamado remoción expedita, mediante el cual un extranjero que arribara sin documentos o con documentos fraudulentos a un puerto de entrada, podría ser deportado sin audiencia alguna. Además, se les quitó a los tribunales la facultad de revisar judicialmente toda orden de remoción. Esto indujo a que los indocumentados pudieran ser objeto de abusos por parte de los agentes de la Patrulla Fronteriza (García y Griego y Verea, 1998; García, 2007).

Si bien leyes como la IIRIRA poco sirvieron para disminuir los flujos migratorios, sí acarrearon consecuencias serias que han hecho de la frontera entre México y Estados Unidos un lugar más peligroso y violento, al incrementarse los costos económicos y los riesgos físicos para quienes pretenden cruzar la frontera de forma indocumentada. La nueva estrategia de control fronterizo implementada incrementó

5- La Ley de Responsabilidad de la Inmigración Ilegal y Reforma, firmada por Clinton en 1996, pretendía lograr un mayor control sobre la inmigración ilegal ampliando los poderes del Servicio de Inmigración y Naturalización (INs) para detener y deportar a inmigrantes sospechosos de ser "ilegales", sin derecho a revisión o apelación judicial.

6- La Ley de Responsabilidad Personal y Reconciliación de Oportunidades de Trabajo (prwora) que el Congreso de los Estados Unidos de América reautorizó en 2002, desvinculó la asistencia de bienestar social (asistencia de dinero en efectivo) y Medicaid creó estrictos requisitos de trabajo para los beneficiarios de dicha asistencia y fijó un límite de por vida de cinco años para los inscritos en dicho programa de bienestar social. 
también los costos económicos para cruzar "ilegalmente" la frontera. Los pagos requeridos por los coyotes a los indocumentados para cruzar la frontera y, muchas veces, conectarlos con los empleadores subió hasta en un 400\% (Cornelius, 2001; Vaira-Lucero et al., 2012).

$\mathrm{Al}$ aumentar el costo y el riesgo de cruzar la frontera se hizo más probable que los inmigrantes permanezcan en Estados Unidos más tiempo. Previo a la aprobación de la IRCA en 1986, la estadía promedio de los indocumentados era de 2.6 años; para 1998, luego de las medidas tomadas por la administración de Clinton, esta cifra aumentó a 6.6 años. Lo cual indica que las políticas migratorias dirigidas a reducir la inmigración indocumentada han tenido poco efecto y que, por el contrario, han motivado la permanencia de los inmigrantes (Griswold, 2002; Berúmen et al., 2011).

El presupuesto del entonces INs fue cada vez más alto. Desde 1993, cuando la cantidad destinada al control migratorio era de mil quinientos millones de dólares, prácticamente se triplicó para 2001, alcanzando los cuatro mil ochocientos millones (ACLU y CNDH, 2009). Lamentablemente, la política migratoria implementada por Estados Unidos consistente en destinar cada vez más dinero para las acciones policíacas, tanto en la frontera como en el interior del país, lo cual solo ha conseguido dividir a las familias e incrementar las cifras de migrantes muertos, sin poder disminuir significativamente la intensidad de los flujos y la presencia de la población indocumentada.

De acuerdo con un informe de la Unión Americana de Libertades Civiles (ACLU por sus siglas en inglés), en equipo con la Comisión Nacional de Derechos Humanos de México ( $\mathrm{CNDH}$ ), indican que desde que inició, en 1994, la llamada Operation Gatekeeper, el número de muertes en la frontera crece significativamente año con año. A partir de 2011, se observó un considerable incremento en el número de muertes, el cual casi se ve duplicado, pues pasó de 415 en 2010 a 767 en 2011. Con esto podemos inferir que los migrantes, aun cuando tienen conocimiento de que Estados Unidos ha endurecido la vigilancia en su frontera Sur, no dudan en tratar de ingresar a la nación norteamericana de forma irregular (Lonegan, 2006; García, 2007).

A pesar del duro ambiente antiinmigrante que se vivió en Estados Unidos durante la década de los noventa, no todo fueron malas noticias para los inmigrantes mexicanos en ese país, ya que como consecuencia de la lucha y demanda, a través de sus organizaciones, en 1996 el Congreso de México aprobó la llamada Ley de Doble Nacionalidad, que fue en realidad una reforma constitucional que redefinía el concepto de nacionalidad. La reforma otorgó a los mexicanos, residentes en el extranjero, el derecho a conservar la nacionalidad mexicana, aunque hubiesen adquirido la de otro país (García y Griego y Verea, 1998; Alarcón, 2007). El hecho benefició significativamente a muchos mexicanos en Estados Unidos que, a pesar de cumplir los requisitos para ello, no habían solicitado la ciudadanía estadounidense, por temor a perder la mexicana. Así, gran cantidad de inmigrantes obtuvieron la ciudadanía para protegerse de las constantes enmiendas legales y políticas antiinmigrantes. Una consecuencia importante de esto fue el incremento en el número de votantes de origen mexicano en Estados Unidos, lo que se tradujo también en una mayor influencia política (Le Texier, 2010).

\section{La era de la seguridad nacional}

La llegada de un nuevo milenio coincidió con el inicio simultáneo de dos administraciones gubernamentales en la región de América del Norte, la de Vicente Fox en México y la del republicano George W. Bush (2001-2008) en Estados Unidos. Al principio, la relación bilateral pareció dar señales de ser 
especial, al producirse una revaloración y una nueva forma de tratar el tema migratorio. Sin embargo, la situación cambiaría dramáticamente en menos de un año. El 11 de septiembre de 2001, en un acto terrorista, fueron atacadas las Torres Gemelas o Centro Mundial de Comercio en Nueva York y el Pentágono estadounidense. Este atroz episodio marcó a la nación norteamericana. Después de este acontecimiento, el debate sobre la inmigración y el control de las fronteras, dejó de ser un asunto económico y político, para convertirse en un tema principalmente de seguridad nacional (Johnson-Garcia, 2015).

Los ataques terroristas impusieron un nuevo paradigma global, la era de la seguridad nacional o de la securitización ${ }^{7}$ (Verea, 2006), tomando dos formas esenciales: la guerra contra el terrorismo, que llevó al despliegue masivo de fuerzas militares estadounidenses en el exterior, particularmente en Irak y Afganistán; y hacia el interior, donde esta ofensiva se manifestó con la implementación de una política de aseguramiento de las fronteras, poniendo especial énfasis en el control de la frontera Sur. De ahí que, surgiera una nueva etapa para la situación de la frontera entre Estados Unidos y México, pues, aunque desde una amplia perspectiva solo fue la continuación, con mayores recursos y alcances de la fase anterior, este nuevo periodo se distinguió por el énfasis que se puso en considerar a la frontera como fuente de amenazas a la seguridad nacional y por congelar el debate sobre una reforma migratoria (Verea, 2006).

Los sucesos del 11 de septiembre desencadenaron un momento de incertidumbre y desaceleración económica que endurecieron la actitud del Gobierno y de la opinión pública, lo que generó un clima preponderantemente anti inmigratorio, que afectó en particular a la población mexicana como a ningún otro grupo en Estados Unidos. El nuevo contexto, aunado al hecho de la presencia de más de 8.5 millones de inmigrantes no autorizados en los Estados Unidos para ese momento, (Jeffrey S. Passel, 2007 Estimates of the Size and Characteristics of the Undocumented Population, Pew Hispanic Center, Washington, 2007, p. 4 http://www.pewhispanic.org/2005/03/21/estimates-of-the-size-and-characteristics-ofthe-undocumented-population/) hizo resurgir la idea xenofóbica de que una célula terrorista pudiera cruzar hacia el territorio estadounidense a través de su porosa frontera Sur, de la misma forma en que un inmigrante cruza como "ilegal". Ante esta situación, la respuesta fue aumentar en los puertos de entrada fronterizos, particularmente en el Sur, la presencia de Agentes Federales y elementos de la Guardia Nacional (Heyman y Ackleson, 2009). Este hecho se hace evidente si se advierte que, mientras en la frontera con México operaban 9300 agentes, solo existían 300 oficiales vigilando la frontera con Canadá (Verea, 2003: 185). Ya desde la época de la administración Carter, el director de la ciA, William Colby, aseveraba que el incremento en los flujos de inmigración procedentes de Latinoamérica, constituían una amenaza mayor para la seguridad del país que la misma Unión Soviética (Jonas, 1998: 408).

Con la aprobación de la Ley Patriota, en el mismo año de 2001, y la Ley de Seguridad Fronteriza Mejorada y de Reforma de Visa de Entrada de 2002, se reforzaron significativamente los poderes del Gobierno Federal en las áreas de vigilancia y detención de sospechosos de terrorismo en áreas fronterizas (Coleman, 2005). En 2002, se aprobó, asimismo, la Ley para la Seguridad Interior (Homeland Security $A c t$ ), que creó el área de seguridad interior, con la finalidad de integrar las 22 agencias federales con responsabilidad sobre seguridad al interior de las fronteras, buscando reducir la vulnerabilidad de Estados Unidos frente al terrorismo (Jorjani, 2008; Heyman y Ackleson, 2009). El Department of Homeland Security (DHs), ha sido la oficina gubernamental de mayor crecimiento, registrando un dramático aumento

7- Traducción tomada de Mónica Verea (2006: 269) de la palabra en inglés "securitization". 
sobre el gasto en seguridad interna, casi triplicando sus recursos asignados en menos de una década, de 19000 millones de dólares en el año fiscal 2002, a 55000 millones en 2010 (Mittelstadt et al., 2011:2). ${ }^{8}$

Muchas de las funciones que poseía el Servicio de Inmigración y Naturalización de Estados Unidos (INS), fueron añadidas al DHS y eventualmente dividas en tres unidades, pertenecientes a este departamento: la Oficina de Aduanas y Protección Fronteriza (СвР por sus siglas en inglés); el Servicio de Ciudadanía e Inmigración de Estados Unidos; y el Servicio de Inmigración y Control de Aduanas (ICE por sus siglas en inglés). Esta última agencia, Immigration and Customs Enforcement (ICE), administra, a su vez, la Office of Detention and Removal Operations como área encargada de vigilar y evitar la inmigración no autorizada. ${ }^{9}$

Las estrategias de seguridad implementadas por la administración de Bush y la legislación emitida por el Congreso entre 2001 y 2002, dieron al gobierno norteamericano, y en particular a sus agencias de seguridad, facultades extraordinarias que estaban por encima del mismo Congreso y el poder judicial, las cuales afectaron los derechos humanos y las libertades civiles de todas las personas, pero perjudicaron más directamente a los inmigrantes, quienes perdieron, prácticamente, toda posibilidad de regularizar su estatus migratorio (Munguía, 2013; Schiavon y Velázquez, 2007).

El 2004 fue un año de elecciones federales en Estados Unidos. Desde 2003, circulaban en el Congreso estadounidense 15 proyectos de ley de reforma migratoria elaborados por legisladores demócratas y republicanos que consideraron que con sus iniciativas podrían obtener el voto de la comunidad latina. A fin de asegurar su reelección, el presidente Bush dio a conocer, en enero de 2004, su propuesta de reforma migratoria que establecía un programa de trabajadores temporales al que podían aplicar los indocumentados que se encontraran trabajando en los Estados Unidos, siempre y cuando salieran del país. La reforma migratoria propuesta por Bush se opuso a otorgar amnistía a los indocumentados, afirmando que se fomentaría la inmigración irregular y se compensaría injustamente a quienes hubieran violado la ley (Tapia, 2006).

El partido demócrata lanzó como candidato a la presidencia al entonces senador por Massachussets, John Kerry, quien también dio a conocer su propuesta de reforma migratoria en los primeros días de 2004, la cual establecía volver a promover el principio de reunificación familiar, otorgar la residencia legal a indocumentados que se encontraran en Estados Unidos, con ciertos años de antigüedad, e implementar una mayor seguridad y protección en la frontera Sur. Asimismo, el candidato demócrata afirmó que durante sus primeros cien días de gobierno enviaría al Congreso un proyecto de ley de reforma migratoria para su evaluación, además de que en el mismo plazo sostendría una reunión con el presidente Fox para hablar de los beneficios que esta reforma traería a los inmigrantes mexicanos.

Evidentemente, tanto el partido demócrata como el republicano, tomaron el tema de una posible reforma migratoria, para atraer el voto de la primera minoría étnica del país, que podría convertirse en la clave para definir al presidente de los Estados Unidos. Finalmente, en 2004 el electorado favoreció la reelección presidencial de Bush, quien, apenas logró este objetivo, diluyó la importancia del tema migratorio, en plena coherencia con el modelo pragmático que este país suele aplicar en estos asuntos.

8- US. Deparment of Homeland Security (2011). Budget-in-Brief Fiscal Year 2011. http://www.dhs.gov/xlibrary/assets/budget_bib_fy2011.pdf

9- Office of Homeland Security, (2002). National Strategy for Homeland Security. http://www.ncs.gov/library/policy_docs/ nat_strat_hls.pdf (junio de 2012). 
La seguridad fronteriza, y no la reforma a las leyes de inmigración, fue la prioridad para Bush y para el Partido Republicano. Bajo este contexto, en diciembre de 2005, surgió la iniciativa para la Ley de Protección Fronteriza, Antiterrorismo y Control de la Inmigración Ilegal, (The Border Protection, Antiterrorism, and Illegal Immigration Control Act), que se conoció como Proposición HR4437, o Ley Sensenbrenner, ${ }^{10}$ presentada y aprobada en la Cámara de Representantes de Estados Unidos, la cual buscaba criminalizar, no solo a los indocumentados, sino a quienes los ayudaran o apoyaran de cualquier forma, ya fueran sus familiares, amigos, vecinos u organizaciones civiles y religiosas.

Entre los puntos más perniciosos de la propuesta Sensenbrenner, estaba tipificar como delito el ingreso de indocumentados y de quienes los protegieran o ayudaran a ingresar al territorio estadounidense. La propuesta consideraba que el Estado se haría cargo de los hijos de los inmigrantes indocumentados que hubieran nacido en Estados Unidos y pretendía rigidizar aún más las disposiciones de la IIRIRA contra los inmigrantes legales (Verea, 2006; Rebolledo, 2008; Durand, 2013). Los partidarios de este proyecto de ley insistían en incrementar el control fronterizo con más agentes de inmigración y aduanas, argumentando que, además de disminuir el tráfico de seres humanos, se ayudaba también a contrarrestar el narcotráfico desde México. Igualmente, se proyectaba la participación de las policías locales como agentes de inmigración para detener extranjeros, y reembolsar los gastos a las entidades que cooperaran para aplicar las leyes federales de inmigración, particularmente en las cuatro entidades (California, Arizona, New Mexico y Texas) que tienen frontera con México (Verea, 2006; Rebolledo, 2008).

Después de una enorme polémica en el Congreso estadounidense, la propuesta Sensenbrenner fue detenida en el Senado, no sin antes generar gran descontento en la comunidad latina, ya que, a pesar de que el proyecto de ley no especificaba sobre qué grupo de inmigrantes estaba dirigida, es un hecho que el mayor número de indocumentados corresponde a esta comunidad. En gran cantidad de ciudades de Estados Unidos estallaron manifestaciones multitudinarias compuestas por inmigrantes, sus familiares y amigos, así como diversos sectores de la sociedad civil. Este movimiento fue denominado como la "Primavera Latina" (Verea, 2006; Durand, 2007; Durand, 2013). En medio de estos sucesos, en mayo de 2005, el presidente Bush ordenó, por segunda ocasión desde el año 2001, el apostamiento de 6000 efectivos de la Guardia Nacional en la frontera entre Estados Unidos y México, a la que denominó Operación Jump Star, como estrategia para aumentar las posibilidades de aprobación de su iniciativa de reforma migratoria en el Congreso; sin embargo, la tan esperada reforma migratoria continuó su impasse político (Tuirán, 2006). Aunque las manifestaciones han continuado y, en ocasiones incluso, aumentan en intensidad, los movimientos antiinmigrantes entre la población estadounidense también han sido exacerbados por políticos conservadores a nivel nacional, al igual que en muchos estados, como estrategia exitosa para atraer el voto.

De hecho, las propuestas de legislación para contener la inmigración se han multiplicado, pasando de 300 presentadas en el año 2005, a 1562 en 2007. Así también sucede con el número de leyes sobre inmigración aprobadas por las legislaturas estatales, las cuales pasaron de 38 leyes aprobadas a 240, en el mismo periodo (Villaseñor y Acevedo, 2009: 417-418). Un ejemplo de la amplia participación de los gobiernos locales en asuntos migratorios ha sido la utilización de la Sección 287(g) de la IIRIRA de 1996,

10- La propuesta H.R. 4437 o Ley Sensenbrenner, fue aprobada por la Cámara de Representantes de Estados Unidos el 16 de diciembre de 2005 con 239 votos a favor y 182 en contra, pero fue rechazada en el Senado. 
la cual permite al Gobierno Federal de Estados Unidos celebrar convenios con agencias estatales para delegar asuntos de inmigración, a fin de que, entre otras cosas, los agentes locales puedan desempeñar funciones policiales en esta materia (Durand, 2013). Esta práctica fue implementada a partir de 2006 en Arizona, Alabama, Florida, Carolina del Norte y California. ${ }^{11}$ Esto ha sido denunciado reiteradamente por organizaciones a favor de los derechos humanos de los inmigrantes. Si bien estas acciones discriminatorias siguen patrones que se han llevado a cabo desde la delimitación misma de la frontera, la etapa de securitización (Verea, 2006), significa la expansión hacia el interior de la 'condición fronteriza' a través de la internación del terror de la deportación (Buff, 2008).

\section{El debate actual sobre inmigración y la importancia del voto latino en Estados Unidos}

La importancia del voto latino en las elecciones presidenciales de Estados Unidos estriba en el hecho de que el sistema electoral de ese país no elige presidente de modo directo, sino mediante la designación por un Colegio Electoral de 538 miembros. Esto es, los ciudadanos registrados a votar eligen realmente a intermediarios o electores miembros del Colegio Electoral, de acuerdo a una asignación por estado, cuyo número se determina por la población de cada entidad. California, por ejemplo, la de mayor población, tiene 55 miembros del Colegio Electoral, mientras que varios de los estados de menor población como Wyoming, Delaware o Vermont cuentan con solo tres miembros electores. El candidato que gana la elección en cada estado, obtiene la totalidad de los electores que deciden en el colegio. Los cambios demográficos de los últimos años, han hecho que los estados con un porcentaje significativo de votantes de origen latino tengan la posibilidad de inclinar la balanza, ya que, de los 50 estados de la nación, realmente nueve o diez están en disputa, los otros están básicamente decididos porque muestran una inclinación histórica muy marcada hacia uno u otro partido. En esos estados "oscilantes" o "de electores indecisos", entre 15\% y $20 \%$ de los votantes son ahora latinos. ${ }^{12}$

El 2007, marcaría el inicio de una profunda recesión económica en Estados Unidos que traería como consecuencia el estancamiento en el crecimiento de la población indocumentada, debido a la falta de empleos y a los cada vez más estrictos controles fronterizos (Passel Jeffrey S. y D’Vera Cohn, 2008; Massey et al., 2009; Durand, 2013). Dado que el origen de la crisis se dio en el sector hipotecario, la industria de la construcción fue la primera actividad económica en presentar signos de agotamiento, con gran repercusión en el ingreso y empleo de la comunidad inmigrante mexicana, ya que es en este sector, junto a los servicios personales, la manufactura y el comercio, donde se ubica mayormente esta mano de obra (Alarcón et al., 2009). Este contexto, que ha provocado precarización y hasta superávit de la provisión de fuerza de trabajo inmigrante, así como un estancamiento de los flujos migratorios, se debe tanto a la falta de empleo, como al aumento de los costos materiales y humanos de la migración por la militarización de la frontera, integrado a las luchas de las comunidades migrantes por la reivindicación de su dignidad y derechos, en un ambiente político muy enrarecido en su contra. Durand (2013), ha interpretado todo esto como una "nueva fase migratoria".

11- Otros estados que han implementado diversos convenios con base en esta disposición son: Virginia, Arkansas, Georgia, Texas, Missouri, Massachusetts, New Jersey, Carolina del Sur, Tennessee, Nevada, Colorado, Rhode Island, Maryland, Ohio, Nuevo México, Oklahoma y New Hampshire.

12- Los estados oscilantes, o divididos en las preferencias electorales, más trascendentes por el número de miembros del Colegio Electoral, son: Florida (29), Pensilvania (20), Ohio (18), Georgia (16) y Carolina del Norte (15). 
Entre 2005 y 2008, en Estados Unidos, se libró una dura batalla por aprobar una reforma migratoria que pudiese resolver la situación de millones de inmigrantes no autorizados, la mayoría de origen hispano. Propuestas de reforma migratoria, como la S.2611, aprobada por el Senado en mayo de 2006, que proponía la regularización de indocumentados con más de cinco años de residencia en ese país, y que podría beneficiar a cerca de siete millones de inmigrantes (Muñoz, 2009), no tuvieron suficiente apoyo legislativo, a pesar de contar con el respaldo del entonces presidente Bush y del candidato presidencial, a la postre ganador en 2008, el Senador demócrata Barack Obama. En contraste, más bien se consolidó una atmósfera de efervescencia conservadora antiinmigrante que provocó la proliferación de leyes y propuestas de leyes y políticas a nivel de los estados, que tenían como claro objetivo limitar los campos de acción laboral y social de la población indocumentada (Durand, 2013; Hastings, 2013).

Obama había sido también, copatrocinador, junto a prominentes miembros del Senado estadounidense como el también demócrata Edward Kennedy y el republicano John McCain, a la postre también candidato presidencial, de la propuesta de reforma migratoria S. 1033, también llamada América Segura e Inmigración Ordenada de 2005. Dicha propuesta contenía, entre otras cosas, aumentar las visas de trabajo y la regularización de indocumentados que reunieran ciertos requisitos, como el no tener antecedentes criminales y contar con el patrocinio de algún empleador (Escamilla, 2008). La S.1033, incluía, asimismo, fortalecer el control fronterizo, la supervisión de quienes contrataran inmigrantes, así como, la coordinación de dependencias federales y locales en esta materia. Paradójicamente, en septiembre de 2006, Obama apoyó la draconiana y anti inmigrante propuesta Sensenbrenner (Escamilla, 2008), ya antes comentada.

En 2008, el Centro Pew Hispanic estimaba en 11.9 millones los inmigrantes indocumentados en Estados Unidos, prácticamente el $4 \%$ de la población de ese país. Aunque la tasa de crecimiento de la población indocumentada se había reducido considerablemente, su número total se había incrementado en más de 40\% desde el 2000, cuando era de 8,4 millones. (Passel y D’Vera, 2008), por otra parte, para 2009 el 63\% de los inmigrantes indocumentados habían llegado después del año 2000 y un $62 \%$ de estos, procedían de México. (Hoefer et al. 2009). Esta situación implicaba que la discusión sobre la inmigración no autorizada, particularmente la de origen mexicano, continuaba siendo un tema por demás relevante.

En las elecciones presidenciales de 2008, Barack Obama (2009-2016), ganaría la presidencia con un apoyo del $67 \%$ de los votantes latinos. Mucho influyó lo acontecido desde la primavera de 2006, y el hecho de que McCain, como candidato presidencial republicano, se aliara con los grupos ultraconservadores antiinmigrantes como el Tea Party, traicionando su inicial convicción de promotor, en el Senado estadounidense, de una reforma migratoria que considerara la regularización de la población indocumentada (Durand, 2013). Entre los principales discursos de su campaña electoral, Obama manifestaba que en su primer año en la presidencia estaría dedicado a intentar regularizar la estancia de los indocumentados en Estados Unidos: "We need immigration reform that will secure our borders, and... that finally brings the 12 million people who are here illegally out of the shadows... We must assert our values and reconcile our principles as a nation of immigrants and a nation of laws". ${ }^{13}$ No obstante, este discurso, para 2009, cuando la administración de Obama inició su primer mandato, enfrentó serias dificultades al 
encontrarse que en ambas cámaras del Congreso existía mayoría republicana. Esto, en conjunto con la recesión que estaba viviendo el país, fueron factores que complicaron sacar adelante una reforma migratoria (Rosenblum, 2011). Durante su primera administración, los temas migratorios fueron soslayados por Obama. La prioridad de su gobierno se inclinó por priorizar el tema económico y dar continuidad al reforzamiento de las políticas de seguridad nacional, concebidas desde la administración anterior, tal y como se evidencia en su discurso, el día 28 de diciembre de 2009, en el cual expresó: "As a nation, we will do everything in our power to protect our country. As Americans, we will never give into fear or division. We will be guided by our hopes, our unity, and our deeply held values. That's who we are as Americans... And we will continue to do everything that we can to keep America safe in the New Year and beyond”. ${ }^{14}$

Ante la imposibilidad en el Congreso Federal por retomar el tema, la inmigración volvería a colocarse en el centro del debate nacional, con base en la promoción desde algunos estados de iniciativas contra los inmigrantes indocumentados, a pesar del hecho de que en Estados Unidos el tema de inmigración, de acuerdo a la Constitución, es competencia exclusiva federal. En Arizona, por ejemplo, la gobernadora Jan Brewer, impulsó y sancionó, en 2010, la propuesta de Ley SB1070. Esta legislación buscaba criminalizar a los inmigrantes que estuvieran residiendo o trabajando en el estado de Arizona sin documentos que lo autorizaran, incrementándose las redadas en centros de trabajo y domicilios. La SB1070 autorizaba a las policías locales solicitar el estatus migratorio a cualquier persona que se considerara sospechosa de ser un inmigrante sin permiso. ${ }^{15}$ De igual manera, se aprobaron en Arizona diversas medidas antiinmigrantes como la Proposición 300, la cual exige a los estudiantes comprobar su estatus migratorio como condición para acceder a cualquier apoyo económico con fondos estatales, por ejemplo, las becas para financiar la educación universitaria, lo cual condenaba a los jóvenes indocumentados a la exclusión de la Educación Superior. Estas leyes han sido ampliamente cuestionadas por algunos sectores de la población estadounidense y la comunidad internacional, por el claro perfil racial de las autoridades migratorias al elegir a su arbitrio a quién interrogar y detener (Eastman, 2012).

Otras iniciativas de ley relacionadas con este escenario antiinmigrante en los Estados Unidos han sido la Proposición S.203, la cual buscaba eliminar los programas para el aprendizaje del idioma inglés dirigidos a estudiantes inmigrantes en las escuelas públicas. Así como las iniciativas SB1308 y SB1309, las cuales intentan negarles la ciudadanía a los niños nacidos en Estados Unidos, cuyos padres no puedan comprobar su estancia legal en el país. Y la iniciativa SB1405, la cual prohíbe la atención médica en hospitales a las personas que carezcan de documentos de residencia, entre muchas otras. La realización de este tipo de propuestas antiinmigrantes ha sido imitada por otras entidades, tal es el caso de Utah, Minnesota Indiana, Georgia, Alabama y South Carolina, regionalizando el problema migratorio (Durand, 2013).

En 2012, al final de su primera administración, la relación de Obama con los votantes de las llamadas minorías, particularmente los hispanos, parecía no estar en su mejor momento. Lejos de llevarse a cabo

14- "Como nación, vamos a hacer todo lo que esté en nuestro poder para proteger a nuestro país. Como estadounidenses, nunca vamos a ceder ante el miedo o la división. Nos guiaremos por nuestras esperanzas, nuestra unidad, y nuestros valores profundamente arraigados. Eso es lo que somos como estadounidenses... y vamos a seguir haciendo todo lo que podamos para mantener seguro a Estados Unidos ahora y en los años siguientes" (traducción propia). Tomado de la página Web de US Department of Homeland Security (2011: 4).

15- En junio de 2012, la Corte Suprema de Estados Unidos, falló en contra de las partes más lesivas de la ley SB1070. Con ello se resta fuerza a la medida, al prohibir a la policía arrestar a personas bajo cargos menores de violación a la ley migratoria. La corte rechazó, asimismo, que sea un crimen el no portar documentos de identificación para probar la estadía legal en Estados Unidos, o para solicitar empleo. 
la reforma migratoria, tan anhelada por los latinos, la deportación de inmigrantes se elevó sustancialmente. Más de 1 millón 600 mil personas fueron expulsadas de Estados Unidos durante el primer periodo de gobierno del presidente Barack Obama (Rodríguez, 2012).

En junio de ese año electoral de 2012, Obama buscó reconciliarse con los votantes latinos, anunciando su orden ejecutiva para amparo temporal de menores indocumentados denominada Deferred Action for Childhood Arrivals, mejor conocida como DACA. La orden presidencial permitió comenzar la entrega de permisos de estadía temporal para cientos de miles de jóvenes indocumentados, principalmente latinos. Los inmigrantes no autorizados que califican para la \acción diferida $\mathbb{X}$ se conocen comúnmente como dreamers, ya que constituyen la mayoría de las personas que cumplen los requisitos generales de la propuesta Development, Relief, and Education for Alien Minors (conocida como DREAM Act). La DREAM Act, es una iniciativa que tiene su antecedente en 2001, cuando se introdujo al Congreso, como Propuesta de Ley S.1291, por los senadores Orrin Hatch (R-UT) y Richard Durbin (D-IL), y por los representantes Howard Berman (D-CA) y Chris Cannon (R-UT), (Immigration Policy Center, 2011). La iniciativa proponía otorgar la residencia condicional a quienes estaban por debajo de la edad de 35 años, y que ingresaron a Estados Unidos antes de los 15 (http://dreamact.info/faq/1\#1n5252). De aprobarse la DREAM Act, no otorgaba estatus legal definitivo, solo detenía la persecución y permitiría a los beneficiarios trabajar o estudiar; y si demostraban ser buenos ciudadanos, podrían acceder a la regularización y posteriormente a la ciudadanía. En mayo de 2006, el contenido de la DREAM Act pasó al senado como un apartado de la Comprehensive Immigration Reform Act de 2006 (CIRA); sin embargo, el Congreso no la aprobó. En 2007 la DREAm Act fue incorporada asimismo en el Proyecto de Ley Kennedy-Kyl; Comprehensive Immigration Reform Bill (S.1639). En el mismo año 2007, se intentó introducir la DREAM Act de forma independiente, pero, al igual que en otras ocasiones, no fue aprobada. Para 2008 y 2010, se pretendió que formara parte del proyecto de ley SA.2237, Department of Defense Authorization Bill, pero fue rechazada nuevamente por la mayoría de los representantes republicanos (Justice for Immigrants, 2010).

A finales de 2010, en el Senado de Estados Unidos se presentó sin éxito, una nueva versión de la DREAM Act, la S.3992, la cual, por primera vez en 10 años de propuestas había sido aprobada en la Cámara de Representantes. La última versión de la DREAM Act, (S. 952), fue presentada en 2011, con más limitaciones respecto a la versión original, por el Senador Durbin (Truax, s/f). La propuesta de Obama se dio también, luego de que en nueve estados se habían aprobado propuestas similares a la DREAM Act ${ }^{16}$ (Durand, 2012).

A pesar de las acciones y propuestas realizadas por el presidente Obama en la contienda por un segundo mandato en la Casa Blanca, paradójicamente, sería su rival republicano Mitt Romney, su principal "aliado" para recuperar la confianza del votante latino. El candidato republicano prometió, durante la campaña, que su modelo de política de inmigración sería similar a la que aplicaban estados como Arizona o Alabama. Además, afirmaba que la solución a la presencia de los indocumentados sería su autodeportación. Romney aseguró, asimismo, que, si era electo presidente, de ser aprobada por el Congreso, vetaría la DREAM Act (Hastings, 2013).

Las medidas tomadas por Obama a favor de los dreamers, aunadas a las poco prudentes declaraciones de Romney, permitirían la reconciliación de Obama con el voto latino, permitiéndole no solo

16- Texas, California, Utah, Washington, Nueva York, Oklahoma, Illinois, Kansas y Nuevo México (posteriormente, también se aprobaron en Nebraska). 
ganar la reelección en 2012, sino además ampliar su margen de aprobación entre este grupo hasta el 73\% (Hastings, 2013).

No obstante, el amplio apoyo que Obama recibió de los latinos, la política de deportaciones y reforzamiento de la frontera continuó durante su segunda administración. Más aún con el mensaje enviado por el Senado, con la aprobación en junio de 2013, de la propuesta de Ley S.744 o Ley para la Seguridad Fronteriza, Oportunidades Económicas y Modernización Migratoria, lo cual implicaba entre otras cosas, dedicar 42500 millones de dólares para el reforzamiento de la frontera con México, lo que incluía continuar la construcción de un muro en la zona limítrofe, así como el uso intensivo de tecnología para la ubicación de personas que intenten cruzar de manera irregular, mediante la implementación de un sistema de radares y aviones no tripulados y la disposición de, por lo menos, veinte mil agentes fronterizos más. ${ }^{17}$

Aunque la propuesta de ley migratoria S. 744, contenía aspectos que favorecían a los inmigrantes indocumentados como oportunidades de regularización y ampliación del número de visas laborales (Moreno, 2013), esta legislación no fue aprobada por la Cámara de Representantes del Congreso estadounidense.

Por otro lado, en noviembre de 2014, el presidente Obama otorgó una nueva acción ejecutiva, la Deferred Action for Parental Accountability (DAPA), la cual preveía otorgar permisos de trabajo de tres años y suspender temporalmente la deportación, principalmente de aquellos que han vivido en los Estados Unidos durante al menos cinco años y tienen hijos ciudadanos estadounidenses o residentes legales, y a los jóvenes que hayan llegado al país antes de cumplir 16 años. Entre DACA y DAPA suman alrededor de 5.2 millones los posibles beneficiarios. Aunque esta última medida de la administración de Obama, que entraría en vigor en febrero de 2015, se encuentra ahora temporalmente suspendida, debido a la decisión de un juez federal y de la decisión de la Suprema Corte de los Estados Unidos en ese mismo sentido, ${ }^{18}$ en términos pragmáticos, las acciones políticas tomadas ya han surtido el efecto para el que fueron diseñadas, que es consolidar el apoyo y simpatía de la mayor parte de los votantes latinos hacia el Partido Demócrata, además de buscar cumplir con las promesas de campaña del presidente Obama y consolidar, según sus propias palabras, "su legado".

Sin embargo, Obama pasará también a la historia como el jefe del ejecutivo estadounidense que ha realizado el mayor número de deportaciones de indocumentados, con un promedio cercano a cuatrocientas mil personas por cada año de su gobierno.

La administración de Obama ha resultado más efectiva para deportar inmigrantes indocumentados que cualquier administración demócrata o republicana anterior. Incluso el número de expulsiones actuales supera por casi diez veces el número de deportaciones realizadas durante los años en que se llevaron a cabo los ostentosos operativos de la Patrulla Fronteriza y el Servicio de Inmigración Nacional en los noventa. ${ }^{19}$ Esta "efectividad" se destacó en la revista The Economist, en su segunda edición de febrero de 2014, en la

17- http://www.informador.com.mx/internacional/2013/467943/6/senado-de-eu-aprueba-reforma-igratoria.htm

18- El Juez Federal Andrew S. Hanen, tomó esta medida de suspensión temporal en respuesta a una demanda interpuesta, en diciembre de 2014, por los gobiernos de 26 estados (24 de estos, regidos por republicanos). El 23 de junio de 2016, se dio a conocer, que la Suprema Corte de los Estados Unidos mantuvo bloqueados los decretos del presidente Barack Obama, que podrían beneficiar a millones de inmigrantes irregulares, a través de los programas D.A.C.A. y D.A.P.A

19- De acuerdo al Departamento de Seguridad Interior de Estados Unidos (DHS). 
cual llamó a la administración presidencial "La máquina de deportación de Obama” (Obama’s deportation machine), y además "concediéndole" al presidente el título de Deportador en jefe (Deporter in Chief). ${ }^{20}$

Obama conduce pragmáticamente agendas políticas paralelas que, a pesar de ser hasta cierto punto contradictorias, permiten atraer la simpatía de la comunidad y particularmente el voto de los latinos, a través de las propuestas de acción ejecutiva que benefician a los dreamers y sus familias, por otra parte, claramente, busca tranquilizar a la generalidad de los electores, ofreciendo una "sensación de seguridad", al venderles la ilusión de tener el control de las fronteras. Estas acciones no solo son electorales y utilitarias, es decir, pragmáticas, sino que en realidad constituyen su único espacio de maniobra, debido al control de ambas cámaras del Congreso por parte de los republicanos. Lo anterior hace vislumbrar que la expectativa de una reforma migratoria integral en Estados Unidos, que contemple la regularización de la mayoría de la población migrante indocumentada, al menos en el corto plazo, resulta ciertamente utópica. El razonamiento es fácil de entender, si consideramos que la capacidad de éxito que el tema migratorio, a favor de una reforma que regularice la situación de millones de indocumentados, ha dado a los demócratas, en el nivel de los comicios presidenciales, es un argumento que se revierte en el nivel de la elección del poder legislativo, debido a que la posición antiinmigrante ha sido una de las principales herramientas electorales de los republicanos para hacerse del control de ambas cámaras del Congreso, en donde se tendría que resolver cualquier reforma migratoria.

No obstante, la poca efectividad que ha tenido la enorme cantidad de leyes decretadas, así como la aplicación de diversas políticas para contener la inmigración indocumentada en los Estados Unidos y que, en buena medida, el aumento de inmigración irregular ha sido provocado por el mal diseño de estas mismas leyes y políticas (Massey et al., 2013; Johnson-Garcia, 2015), el ambiente político continua traduciéndose en la promulgación de diversas leyes federales que criminalizan la presencia de inmigrantes indocumentados.

Por otro lado, tomando en cuenta las propuestas sobre inmigración de Donald Trump que le sirvieron para ganar la candidatura por el Partido Republicano en la elección primaria, que han sido la construcción de un muro fronterizo, así como realizar una deportación masiva de la población indocumentada, particularmente de la de origen mexicano, a quienes ha llamado criminales y violadores. Y ante un panorama de una sociedad estadounidense ampliamente dividida y polarizada respecto al tema migratorio, ${ }^{21}$ obliga a los demócratas, incluida Hillary Clinton, su candidata presidencial, a buscar permanecer en una posición política conservadora, a pesar del discurso de apoyar una reforma que contenga la regularización de la inmigración no autorizada. Así parecen advertirlo también los votantes hispanos, ya que los sondeos de opinión, de dos meses antes de la elección presidencial, dan a Clinton, un porcentaje de intención de voto entre los latinos del 70\%, similar al obtenido por otros candidatos demócratas, a pesar de las posiciones extremistas, anti inmigrantes y anti mexicanas de Trump. ${ }^{22}$

Conviene hacer aquí una última acotación, el hecho de que empezamos a enfrentar una nueva coyuntura económica en los Estados Unidos, ya que el mismo presidente Obama, en su discurso de “El Estado

20- Artículo de la edición de febrero de 2014, de la revista The Economist.

21- Editorial de la revista The Economist del 5 de marzo de 2016.

22- Artículo de la reportera Abby Philip, en la edición del 2 de septiembre de 2016 del periódico The Washington Post, disponible en: https://www.washingtonpost.com/politics/clinton-isnt-doing-better-than-previous-democrats-with-latinos-even-against-trump/2016/09/02/9daa792a-7052-11e6-8365-b19e428a975e_story.html 
de la Unión”, el 21 de enero de 2015, declaró el fin de la crisis y el inicio del crecimiento económico: “... after a breakthrough year for America, our economy is growing and creating jobs at the fastest pace since 1999. Our unemployment rate is now lower than it was before the financial crisis... The shadow of crisis has passed, and the State of the Union is strong." ${ }^{23}$ Esta situación de crecimiento de la economía estadounidense pudiera incrementar la demanda de mano de obra inmigrantes, aunque con la provisión actual que significan los 12 millones de indocumentados, la lógica pragmática no permite entrever la posibilidad real de regularizar el estatus de esta amplia población inmigrante. No obstante, lo declarado en el discurso de Obama sobre el Estado de la Unión, de enero de 2015, acerca del fin del periodo más crítico de la economía estadounidense, la prevalencia de una situación recesiva de la economía en muchos estados y regiones, ha ayudado electoralmente a los republicanos, permitiéndoles obtener el control de ambas cámaras del congreso federal.

\section{Conclusiones}

Como se planteó en la introducción, la elaboración de leyes y políticas migratorias en los Estados Unidos se ha sustentado históricamente en un sistema pragmático, que persigue el equilibrio entre grupos hegemónicos de interés político y económico, de acuerdo a los partidos y regiones, así como a las negociaciones y acuerdos entre estos. Este modelo de pragmatismo es independiente de qué partido político se encuentre en la presidencia del país u obtenga la mayoría en el Congreso.

A lo largo del siglo xIX, y durante los primeros años del siglo xx, Estados Unidos consideró irrelevante la necesidad de controlar la inmigración, a la cual fomentaba, pues se había convertido en un elemento estructural de su economía. La inmigración mexicana, que prácticamente nació con la Independencia de Texas en 1836, continuó llegando durante los siglos XIX y xx, reforzando colonias de inmigrantes mexicanos tanto en el norte industrializado, como en el medio Oeste y sobre todo en la región del Suroeste.

A partir de la década de los veinte del siglo pasado, Estados Unidos aplicó una política que consiste en alternar periodos de inmigración a gran escala con deportaciones masivas. La Segunda Guerra Mundial provocó que, en 1942, a instancias de Estados Unidos, México firmara los acuerdos de braceros. Este programa llevó de manera legal, durante 22 años, a cerca de cinco millones de trabajadores mexicanos. Una cantidad similar cruzara la frontera sin documentos, debido a que la fuerte demanda laboral en Estados Unidos no alcanzaba a ser cubierta por medio del referido acuerdo migratorio.

Impulsado por una situación de recesión económica, desde los setenta, se inició en el Congreso de Estados Unidos un intenso debate por reformar las leyes de inmigración, que posteriormente culminó con la aprobación de la Ley de Reforma a la Inmigración (IRCA) en 1986. La IRCA aumentó considerablemente el presupuesto del Departamento de Inmigración, al tiempo que estableció sanciones a empleadores de indocumentados y una amnistía que regularizó la situación de cerca de tres millones de personas, la mayoría de origen mexicano.

23- “...después de un año decisivo para los Estados Unidos, nuestra economía está creciendo y creando puestos de trabajo a un ritmo más acelerado desde 1999. Nuestra tasa de desempleo es ahora más baja de lo que era antes de la crisis financiera... La sombra de la crisis ha pasado, y el Estado de la Unión es fuerte. (traducción propia). http://edition.cnn.com/2015/01/20/ politics/state-of-the-union-2015-transcript-full-text/ 
A través de las últimas tres décadas, las administraciones presidenciales y el Congreso estadounidense, ya sea controlado por republicanos o demócratas, han compartido múltiples propuestas draconianas contra la inmigración indocumentada. En los noventa, el ambiente político estadounidense se enrareció aún más sobre la presencia de este grupo. En 1993, iniciaron las políticas disuasivas de corte militar, con diversas acciones que recibieron nombres como Operación Bloqueo, Guardián y Salvaguardia, entre otras. En 1994, surgió la Propuesta 187 en California, que buscaba negar el acceso a los servicios públicos a los inmigrantes. Y en 1996, el Congreso estadounidense aprobó leyes represivas como IIRIRA y PRWORA que buscaban quitar a los inmigrantes, irregulares o legales, el derecho a servicios gratuitos federales, como los de asistencia médica y alimenticia.

Con los acontecimientos del 11 de septiembre de 2001, el Congreso y el Gobierno de Estados Unidos han reforzado más las leyes y medidas de control de la inmigración, respondiendo y exacerbando, al mismo tiempo, las actitudes xenófobas y nativistas por parte de ciertos grupos de la sociedad estadounidense. Las legislaciones y políticas migratorias que criminalizan la migración indocumentada, paradójicamente, han incentivado la consolidación de las comunidades migrantes en Estados Unidos y solo han provocado la división y sufrimiento de las familias y el aumento en el número de muertes al cruzar la frontera.

Las iniciativas estatales ante la problemática migratoria hacen ver estrechas las leyes y políticas nacionales. Leyes como la SB1070 de Arizona o la HB56 de Alabama, dan cuenta de que las decisiones locales llevan más a fondo la xenofobia y represión, contraponiéndose incluso a lo que expresan los discursos a nivel nacional. Vemos pues, una política migratoria que, escudándose en el antiterrorismo, militariza fronteras, sin lograr frenar los sueños de miles de migrantes, principalmente de mexicanos y latinoamericanos, que no dudan en seguir teniendo a la nación americana como la solución a los problemas socioeconómicos que viven día a día al Sur de la línea fronteriza. Los migrantes, como actores fundamentales de toda esta problemática, no han permanecido estáticos. A partir de la primavera de 2006, millones de personas en Estados Unidos han salido a las calles para exigir una reforma migratoria integral, basada en los principios de reunificación familiar y en el reconocimiento de que el país necesita a los cerca de doce millones de inmigrantes indocumentados, que actualmente se reconoce existen. Aunque la conciencia, unidad y organización de los inmigrantes ha crecido, los resultados concretos no han sido muy satisfactorios. De hecho, la situación en general ha empeorado en los últimos años, ya que, aunado a las leyes y políticas xenófobas que se promueven a nivel local, como las de Arizona o Alabama, en la administración del presidente Obama las deportaciones de inmigrantes indocumentados se han disparado.

A partir de la revisión del contexto histórico de la política migratoria de los Estados Unidos, podemos concluir que el Estado-nación estadounidense se originó con base en una mezcla de valores morales puritanos e intereses económicos de las élites fundadoras, que desembocaron en leyes y políticas de inmigración basadas en el racismo, así como en intereses económicos y geopolíticos pragmáticos. Analizar el contexto histórico, en el cual se formulan y aplican las leyes y políticas en materia de inmigración en Estados Unidos, nos puede ayudar a entender por qué en el presente no existe un consenso hacia el desarrollo de una política migratoria integral que sea congruente con la realidad económica, social y cultural de ese complejo país.

A través de la historia, independientemente del partido político que ocupe la Casa Blanca o tenga la mayoría en el Congreso, se ha seguido este modelo de pragmatismo, que acuerda la formulación y 
modificación de las iniciativas de ley o aplicación de políticas migratorias, a las coyunturas políticas o circunstancias económicas prevalecientes, pasando por alto, en ocasiones, la aplicación estricta de las propias leyes vigentes.

Con base en todo lo anterior, podemos vislumbrar que hoy en día el creciente rechazo al fenómeno de la inmigración indocumentada, así como las posiciones encontradas que prevalecen entre congresistas demócratas y republicanos sobre el tema, sumadas a las prioridades internas y de política exterior de Estados Unidos, anulan prácticamente cualquier posibilidad de que se apruebe una reforma migratoria a favor de los trabajadores indocumentados, tanto en lo que resta de la administración de Obama como en un futuro inmediato. Más aún que las propuestas del Candidato republicano Donald Trump, así como la mayoría de los miembros del congreso de este mismo partido político y de algunos de los del bando demócrata, ha sido en contra de cualquier regularización de la inmigración indocumentada.

A menos que las condiciones económicas de Estados Unidos cambien sustancialmente en el futuro cercano o que la situación política incline la balanza en favor de los indocumentados, ya sea por el factor político demográfico de los nuevos votantes que han surgido de inmigrantes regularizados o sus descendientes o familiares nacidos en ese país, en particular de los latinos, o por medio de la presiones ejercidas por las organizaciones civiles que luchan por favorecer los derechos de los inmigrantes, las cosas seguirán igual en materia de inmigración irregular.

En suma, todo parece indicar que no cabe la expectativa, al menos en el corto plazo, de que se presente una reforma migratoria que contemple una amplia amnistía para los inmigrantes irregulares. En el mejor de los casos, se podría esperar una propuesta de reforma migratoria llena de complejidades, dificultades y limitaciones, pues como se ha demostrado a lo largo de este texto, las leyes y políticas migratorias estadounidenses obedecen más a las coyunturas políticas y económicas del devenir histórico, así como al acuerdo entre las elites en estados Unidos. Y, las actuales circunstancias, no son favorables para la aprobación de una reforma migratoria, amplia e integral, que satisfaga las expectativas y necesidades de la mayoría de los inmigrantes.

Por último, no podemos dejar de mencionar que, el marco de normas jurídicas y políticas de Estados Unidos, una de las sociedades más ricas del mundo, donde se cataloga al inmigrante indocumentado como "ilegal", continúa sosteniéndose, paradójicamente, en un sistema de sobreexplotación con condiciones de discriminación, esta vez con base en el estatus migratorio de las personas.

\section{Referencias}

Adams, Paul. 2013. Los Estados Unidos de América. México. D.F.: Siglo xxı Editores.

Alarcón, Rafael. 2007. Hacia la construcción de una política de emigración en México. Instituto de los Mexicanos en el Exterior. pp. 157-170. http://www.ime.gob.mx/investigaciones/bibliografias/politica mexico.pdf (22 de mayo de 2014).

2011. U.S. Immigration Policy and the Mobility of Mexicans (1882-2005). Migraciones Internacionales 6 (1): 185-218. http://www.colef.mx/migracionesinternacionales/revistas/MI20/MI_20-185-218. pdf (23 de junio de 2013).

Alarcón, Rafael, Rodolfo Cruz, Alejandro Díaz-Bautista, Gabriel González Köing, Antonio Izquierdo, 
Guillermo Yrizar y René Zenteno. 2009. La crisis financiera en Estados Unidos y su impacto en la migración mexicana. Migraciones Internacionales 5 (1): 193-210.

Albertí, Alfonsina. 2012. Una reflexión teórica en torno a las migraciones laborales, a través del caso histórico del Programa Braceros (1942-1964). Nómadas: Revista Crítica de Ciencias Sociales y Jurídicas Núm. Especial: América Latina. http://www.redalyc.org/articulo.oa?id=18126163020 (4 de abril de 2013).

Andreas, Peter. 2000. Border games. Policing the US-Mexico divide. Nueva York: Cornell University Press. Berúmen, Salvador, Luis Ramos e Isabel Ureta. 2011. Migrantes mexicanos aprehendidos y devueltos por Estados Unidos. Estimaciones y características generales. Apuntes sobre migración No.2 Primera Edición: 1-10. México, D.F.: Centro de Estudios Migratorios del Instituto Nacional de Migración. http://www. politicamigratoria.gob.mx/es_mx/SEGOB/apuntes_sobre_migracion_No_2 (11 de febrero de 2013). Buff, Rachel. 2008. The deportation terror. American Quarterly 60 (3): 523-551. DOI: https://doi. org/10.1353/aq.0.0028

Bustamante, Jorge. 1997. Cruzar la línea. La migración de México a los Estados Unidos. México, D. F.: Fondo de Cultura Económica.

Calavita, Kitty. 1989. The Contradictions of immigration lawmaking: The immigration reform and control act of 1986. Law \& Policy 11 (1): 17-47. DOI: https://doi.org/10.1111/j.1467-9930.1989.tb00019.x Castles, Stephen y Simona Vezzoli. 2009. The global economic crisis and migration: temporary interruption or structural change? Paradigmes (2): 68-75.

Chang, Elaine. 2010. Social workers and the bracero program: Working within migration discourse and conflicting policy. http://nature.berkeley.edu/classes/es196/projects/2010final/ChangE_2010.pdf (18 de abril de 2013).

Coleman, Mathew. 2005. U.S. statecraft and the U.S.-Mexico border as security/economy nexus. Political Geography (24): 185-209. DOI: https://doi.org/10.1016/j.polgeo.2004.09.016

Cornelius, Wayne. 1989. La demanda de fuerza de trabajo mexicana en los Estados Unidos. En Flujos migratorios mexicanos hacia Estados Unidos, coordinado por Jorge Bustamante y Wayne A. Cornelius. México, D.F.: Fondo de Cultura Económica.

2001. Death at the border: Efficacy and unintended consequences of US immigration control policy. Population and Development Review 27 (4): 661-685. DOI: https://doi.org/10.1111/j.17284457.2001.00661.x

Dunn, Timothy. 1996. The militarization of the U.S.-Mexico border, 1978-1992: Low intensity conflict doctrine comes home. CMAS Books. Center for Mexican American Studies, University of Texas at Austin. Austin: University of Texas Press.

Durand, Jorge y Douglas Massey. 2002. Beyond smoke and mirrors. Mexican immigration in an age of economic integration. Nueva York: Russell Sage Foundation.

Durand, Jorge. 1994. Más allá de la línea: patrones migratorios entre México y Estados Unidos. Colección Regiones. México, D.F.: Consejo Nacional para la Cultura y las Artes.

2006. Programas de trabajadores temporales. Evaluación y análisis del caso mexicano. México: Consejo Nacional de Población.

2007. El Programa Bracero (1942-1964). Un balance crítico. Migración y Desarrollo (9): 27-43. 2012. Los dreamers. Contracorriente. 01 de julio. http://www.educacioncontracorriente.org/ar- 
chivo/index.php?option=com_content\&view=article\&id=52112\%3Alos-dreamers-jorge durand\&catid $=14 \% 3$ Amaestros\&Itemid=60 (15 de junio de 2013). 2013. Nueva fase migratoria. Papeles de Población 19 (77): 83-113.

Eastman, John. 2012. Papers, please: Does the constitution permit the states a role in immigration enforcement? Harvard Journal of Law \& Public Policy 35 (2): 569-592.

Escamilla, Patricia. 2008. Posiciones de Barack Obama en materia de migración y seguridad fronteriza. Colegio de la Frontera Norte. https://www.colef.mx/evento/posiciones-de-barack-obama-en-materiade-migracion-y-seguridad-fronteriza/ (1 de septiembre de 2016).

Esquivel, Manuel. 2009. La migración de trabajadores mexicanos a los Estados Unidos de América. En Temas de migración y derecho, coordinado por David Cienfuegos Salgado, Manuel de Jesús Esquivel Leyva y Julieta Morales Sánchez, pp. 83-89. Biblioteca Jurídica Virtual del Instituto de Investigaciones Jurídicas de la UNAM.

Fullerton, Thomas y Patricia Barraza. 2009. Developing the U.S-Mexico border region for a prosperous and secure relationship: Managing migration flows. Binational Research Paper. James A. Baker III Institute for Public Policy Rice University. http://bakerinstitute.org/files/documents/u.s.-mexico-border-project-binational-research-papers/LAI-pub-BorderSecFullertonBarraza-033009.pdf (9 de julio de 2014). García, Ismael. 2003. Confeccionando desilusiones: trabajadoras mexicanas de la costura en Los Ángeles. Culiacán, México: UAS-DIFOCUR.

2007. Vidas compartidas. Formación de una red migratoria transnacional: Aguacaliente Grande, Sinaloa y Victor Valley, California. México, D.F.: Plaza y Valdés.

García y Griego, Manuel y Mónica Verea. 1998. México y Estados Unidos frente a la migración de indocumentados. México D.F.: Miguel Ángel Porrúa.

González, Moisés. 2008. Efectos sociales de la crisis de 1929. El Colegio de México. pp. 536-558. http:// codex.colmex.mx:8991/exlibris/aleph/a18_1/apache_media/HBVJHQ3GE7LDC5NLN8BIEYIKSIQYK9.pdf (11 de marzo de 2013).

Griswold, Daniel. 2002. Willing workers. Fixing the problem of illegal mexican migration to the United States. The Trade Policy Analysis (19). Washington, DC: Cato Institute. http://www.cato.org/publications/ trade-policy-analysis/willing-workers-fixing-problem-illegal-mexican-migration-united-states $(9 \mathrm{de}$ febrero de 2013).

Hackett, Patricia. 2006. Chinese exclusion act records. A neglected genealogical source. Association of Professional Genealogists Quarterly March: 25-30. http://www.familytraces.com/wp-content/uploads/2015/11/CEAAPGQMar06.pdf (15 de marzo de 2013).

Hanson, Gordon. 2009. The economics and policy of illegal immigration in the United States. Washington, DC: Migration Policy Institute. http://irps.ucsd.edu/assets/037/11124.pdf (12 de marzo de 2013). Hamann, Edmund, Víctor Zúñiga y Juan Sánchez. 2008. From Nuevo León to the USA and back again: Transnational Students in Mexico. Journal of Immigrant \& Refugee Studies 1 (79): 60-84. http://digitalcommons.unl.edu/teachlearnfacpub/79 (6 de julio de 2012).

Hastings, Maribel. 2013. Una carrera de obstáculos. La reforma migratoria en Estados Unidos. Foreign Affairs Latinoamérica 13 (3): 7-11.

Heyman, Jason y Josiah Ackleson. 2009. United States Border Security after 9/11. In Border Security in the al-Qaeda Era, editado por John Winterdyk y Kelly Sundberg, pp. 37-75. New York: CRC Press. 
Hoefer, Michael, Nancy Rytina y Bryan Baker. 2009. Estimates of the unauthorized immigrant population residing in the United States: January 2008. Office of Immigration Statistics, Policy Directorate, U.S. Department of Homeland Security. http://www.dhs.gov/xlibrary/assets/statistics/publications/ois_ill_ pe_2008.pdf (31 de agosto de 2016).

Hollifield, James, Valerie Hunt y Daniel Tichenor. 2008. Immigrants, markets, and rights: The Un ited States as an emerging migration state. Washington University Journal of Law \& Policy 27 (7): 7-44.

Hollifield, James, Philip Martin y Pia Orrenius. 2014. Controlling immigration. A global perspective. Stanford, California: Stanford University Press.

Immigration Policy Center. 2011. The DREAM act. Creating opportunities for immigrant students and supporting the U.S. economy. http://www.immigrationpolicy.org/just-facts/dream-act (20 de enero de 2012).

Justice for Immigrants. 2010. DREAM Act: Background information. http://www.justiceforimmigrants. org/documents/dream-act-backgrounder.pdf (25 de agosto de 2013).

Jimenez, Maria. 2009. Humanitarian crisis: Migrant deaths at the U.S.-Mexico border. ACLU of San Diego and Imperial Counties and Mexico's National Commission of Human Rights. http://www.aclu. org/sites/default/files/field_document/humanitariancrisisreport.pdf (5 de diciembre de 2011).

Jiménez, Tomás. 2011. Immigrants in the United States. How well are they integrating into society? Washington, DC: Migration Policy Institute. http://www.migrationpolicy.org/pubs/integration-Jimenez. pdf. (11 de octubre de 2013).

Jonas, Susana. 1998. Seguridad nacional estadounidense vs. bienestar nacional para la base para una política migratoria. En Migración y Frontera, coordinado por Manuel Castillo, Alfredo Lattes y Jorge Santibañez, pp. 403-424. México, COLEF/Asociación Latinoamericana de Sociología/El Colegio de México.

Johnson-Garcia. 2015. Chronology of culmination: The effects of U.S. legislation on illegal mexican immigration from 1875-2011. Editor So Squeaky, LLC.

Jorjani, Raha. 2008. Detention, deportation, and the immigration consequences of criminal convictions: An overview. Iranian American Bar Association. http://www.iaba.us/publications/Working\%20Document\%202\%20Detention\%20Deportation\%20and\%20the\%20Immigration\%20Consequences $\% 20$ of\%20Criminal\%20Convictions\%20-\%20An\%20Overview.pdf (7 de diciembre de 2012).

Kerwin, Donald y Serena Yi-Ying Lin. 2009. Immigration detention. Can ICE meet its legal imperatives and case management responsabilities? Washington, DC: Migration Policy Institute. http://www.migrationpolicy.org/pubs/detentionreportSept1009.pdf (7 de abril de 2014).

Kiser, Martha. 1979. Mexican workers in the United States: Historical and political perspectives. Albuquerque: University of New Mexico Press.

Laborde, Adolfo A. 2011. El fenómeno migratorio de los mexicanos en Estados Unidos a través de tres etapas históricas de México: 1810, 1910 y 2010. http://rimd.reduaz.mx/ponencias_flacso/PonenciaAdolfoLaborde.pdf (17 de mayo de 2012).

Le Texier, Emmanuelle. 2003. Reseña de "La dimensión política de la migración mexicana", de Leticia Calderón Chelius y Jesús Martínez Saldaña. Migraciones internacionales 2 (1): 176-178.

Lonegan, Bryan. 2007. American diaspora: The deportation of lawful residents from the United States and the destruction of their families. N.Y U. Review of Law \& Social Change 32 (1): 55-81.

Manges, Karen. 2008. Consequences of the national origins act. pp. 938-939. www.shsu.edu/ kmd007/ 
- Revista de Ciencias Sociales y Humanidades. ISSN-P: 0188-9834 ISSN-E: 2395-8669.

documents/WinFSHD2Userskmd007ArticlesDouglas-NationalOriginsSystem-1.pdf (13 de mayo de 2012).

Marmora, Lelio. 2002. Políticas de migraciones internacionales. México: Paidós/ Mexicana/orm. Martin, Philip. 2014. The United States. The continuing immigration debate. En: Controlling immigration. A global perspective, coordinado por James Hollifield, Philip Martin y Pia Orrenius. Stanford, California. Stanford University Press.

Massey, Douglas. 2008. La racialización de los mexicanos en Estados Unidos: estratificación racial en la teoría y en la práctica. Migración y Desarrollo (10): 65-95.

Massey, Douglas, Jorge Durand y Malone Nolan. 2002. Beyond Smoke and Mirrors: Mexican Immigration in an Era of Economic Integration. Nueva York: Russell Sage Foundation.

Massey, Douglas y Mariano Sana. 2003. Patterns of U. S. migration from Mexico, the Caribbean and Central America. Migraciones Internacionales 2 (2): 5-39.

Massey, Douglas, Karen Pren y Jorge Durand. 2009. Nuevos escenarios de la migración México-Estados Unidos. Las consecuencias de la guerra antiinmigrante. Papeles de Población, 15(61): 101-128.

Massey, Douglas y Karen Pren. 2013. La guerra de los Estados Unidos contra la inmigración. Efectos paradójicos. Documents d’Anàlisi Geogràfica. Vol. 59(2): 209-237.

Mendoza, María y Graciela Tapia. 2011. Situación demográfica de México 1910-2010. Fondo de Población de las Naciones Unidas. http://www.unfpa.org.mx/publicaciones/cuadro_4.pdf (4 de julio de 2012).

Mercado, Asael y Miguel Ángel Piña. 2010. Migración hacia Estados Unidos y su impacto en la nueva reforma migratoria. Espacios Públicos 13 (27): 216-235.

Mercado, Horacio y Marisol Palmerín. 2009. Causas y consecuencias de la migración de mexicanos a los Estados Unidos de América. http://www.eumed.net/libros/2009c/597/ (9 de enero de 2014).

Mittelstadt, Michelle, Burke Speaker, Doris Meissner y Muzaffard Chishti. 2011. Through the prism of national security: Major immigration policy and program changes in the decade since $9 / 11$. Washington, DC: Migration Policy Institute. http://www.migrationpolicy.org/pubs/FS23_Post-9-11policy.pdf (20 de abril de 2014).

Morales, Patricia. 1989. Indocumentados mexicanos. Causas y razones de la migración laboral. México, D.F.: Grijalbo.

Moreno, Salvador. 2013. La reforma migratoria en los Estados Unidos. Posibilidades y alcances. Documento de Trabajo, $\mathrm{N}^{\circ}$ 161. Centro de Estudios Sociales y de Opinión Pública (CESOP). Cámara de Diputados, LX Legislatura.

Munguía, Alex. 2013. La política migratoria en América del Norte y la seguridad nacional. En Migraciones globales. Experiencias regionales y enseñanzas para México, coordinado por Ismael García y Alex Munguía, pp. 359-377. México, D.F.: Jorale Editores-UAs.

Muñoz, Tomás. 2009. Causas y consecuencias de la fallida reforma migratoria en Estados Unidos: una de las grandes deudas en la presidencia de George W. Bush. Revista de Relaciones Internacionales de la UNAM, 105: 135-151.

Narváez, José. 2006. Wet history: itinerario histórico de la condición jurídica del mexicano emigrado a Estados Unidos. Biblioteca Jurídica Virtual del Instituto de Investigaciones Jurídicas de la UNAM. pp. 487-503. http://www.juridicas.unam.mx/publica/librev/rev/hisder/cont/18/pr/pr25.pdf (22 de julio de 
2014).

Office of Homeland Security. 2002. National Strategy for Homeland Security. http://www.ncs.gov/library/policy_docs/nat_strat_hls.pdf (9 de septiembre de 2012).

Orozco, José. 1992. Razón de Estado y razón de mercado. Teoría y pragma de la política exterior norteamericana. México, D.F.: Fondo de Cultura Económica. 1996. El Estado pragmático. México, D.F.: Fontamara/UnAm. 2001. De teólogos pragmáticos y geopolíticos, aproximación al globalismo norteamericano. México, D.F.: Gedisa Editorial/FCPYS-UNAM. 2004. El siglo del pragmatismo político. México, D.F.: Fontamara/UnAM. 2010. La odisea pragmática. México, D.F.: FCPYs-UnAM/Fontamara.

Passel, Jeffrey. 2007. Estimates of the size and characteristics of the undocumented population, Pew Hispanic Center, Washington. http://www.pewhispanic.org/2005/03/21/estimates-of-the-size-and-characteristics-of-the-undocumented-population/ (31 de agosto de 2016).

Passel, Jeffrey y D’Vera Cohn. 2008. Trends in unauthorized immigration: Undocumented inflow now trails legal inflow. Pew Research Center. http://www.pewhispanic.org/2008/10/02/trends-in-unauthorized-immigration/ (31 de agosto de 2016).

Pesce, Helen Julitta. 2008. Operation Wetback and the Bracero Program. pp. 73-83. http://www.umsl. edu/ umslhistory/PsiPsi/Spring_08/6Wiley\%20on\%20Operation\%20Wetback\%20Bracero\%20Program.pdf (14 de mayo de 2012).

Philip, Abby. 2016. The Washington Post. Edición electrónica del 2 de septiembre. En: https://www. washingtonpost.com/politics/clinton-isnt-doing-better-than-previous-democrats-with-latinos--evenagainst-trump/2016/09/02/9daa792a-7052-11e6-8365-b19e428a975e_story.html (3 de septiembre de 2016).

Pinedo, Moisés. 2009. Inmigración ilegal: un estudio sobre los ministerios hispanos en los Estados Unidos y la responsabilidad cristiana ante el gobierno. Estados Unidos: Apologetics Press. http://espanol.apologeticspress.org/pdfs/e-books_pdf/imm-es.pdf (5 de julio de 2014).

Rebolledo, Jorge. 2008. Fronteras porosas: el caso de México y Estados Unidos. Revista Enfoques: Ciencia Política y Administración Pública 6 (8): 173-191.

Rodríguez, Roberto. 2009. Migración de personal altamente calificado de México a Estados Unidos: una exploración del fenómeno. Revista Electrónica de Investigación Educativa 11(2): 1-34.

Rosenblum, Marc. 2011. US immigration policy since 9/11: Understanding the stalemate over comprehensive immigration reform. Washington, DC: Migration Policy Institute. http://www.migrationpolicy. org/pubs/RMSG-post-9-11 policy.pdf (9 de mayo de 2013).

Rude, Cristopher. 2009. The world economic crisis and the Federal Reserve's response to it: August 2007-December 2008. Studies in Political Economy. http://www.peri.umass.edu/fileadmin/pdf/conference_papers/SAFER/Rude_World_Economic.pdf (12 de mayo de 2013).

Rubio, Rodolfo. 2011. Cambios en el patrón migratorio y vulnerabilidades de los migrantes indocumentados mexicanos con destino y desde Estados Unidos. Fundación Ciudadanía y Valores. Simposio Internacional de Inmigración y Globalización. http://www.funciva.org/uploads/ficheros_documentos/1295951537_rodolfo_rubio.pdf (25 de junio de 2013).

Rytina, Nancy. 2002. IRCA legalization effects: Lawful permanent residence and naturalization through 
2001. Paper presented at The Effects of Immigrant Legalization Programs on the United States: Scientific evidence on immigrant adaptation and impacts on U.S. economy and society, The Cloister, Mary Woodward Lasker Center.

Serrano, María. 2010. La crisis económica de 1929: Roosevelt y el new deal. Revista de la Facultad de Ciencias Sociales y Jurídicas de Elche 1 (6): 112-130.

Storrs, Larry. 2006. Mexico's importance and multiple relationships with the United States. Congressional Research Service. The Library of Congress. http://www.au.af.mil/au/awc/awcgate/crs/rl33244.pdf (9 de abril de 2012).

Tapia, Carlos. 2006. Los programas de trabajadores temporales en la política migratoria estadounidense y la propuesta del presidente Bush. Norteamérica 1 (1): 247-258.

The Economist. 2014. Immigration. Barack Obama, Deporter-in-chief. /Leaders/. February $8^{\text {th }}-14^{\text {th }}$.

The Economist. 2016. The primaries. Battle Lines. /editor's Picks/ March 5TH-11TH

U.S. Department of Homeland Security. 2011. Budget-in-Brief Fiscal Year 2011. http://www.dhs.gov/ xlibrary/assets/budget_bib_fy2011.pdf (9 de octubre de 2013).

Truax, Eileen. s/f. Estrategias para concretar el sueño: protección e integración de Dreamers que vuelven a casa. Cuarto Coloquio de Migración Internacional Políticas y Acciones de Protección de la Población Migrante http://www.gobernacion.gob.mx/work/models/SEGOB/Resource/2301/1/images/Eileen\%20 Truax(1).pdf (3 de septiembre de 2016).

Tuirán, Rodolfo. 2006. La reforma migratoria pendiente. Migraciones Internacionales 3 (4): 161-173. Vaira-Lucero, Matias, Nahm Daehoon y Tani Massimiliano. 2012. The impact of the 1996 US immigration policy reform (IIRIRA) on mexican migrants' remittances. IZA Discussion Paper (6546). http://ftp. iza.org/dp6546.pdf (9 de junio de 2013).

Velázquez, Rafael y Jorge Schiavon. 2007. El 11 de septiembre y la relación México-Estados Unidos: ¿hacia la securitización de la agenda? Revista Enfoques: Ciencia Política y Administración Pública 6 (8): 61-85. Verea, Mónica. 2003. Migración temporal en América del Norte: propuestas y respuestas. México: CISANUNAM.

2006. ¿Hacia una reforma migratoria? Norteamérica 1 (2): 265-287.

Villaseñor, Rodrigo y Luis Acevedo. 2009. La actividad legislativa estatal vinculada con la inmigración y los inmigrantes en Estados Unidos. En El estado de la migración. Las políticas públicas ante los retos de la migración mexicana en Estados Unidos, coordinado por Paula Leite y Silvia E. Giorguli, pp. 415-438. México D.F.: Consejo Nacional de Población.

Wasem, Ellen. 2010. Immigration reform issues in the 111th Congress. Congressional Research Service. http://www.nationalaglawcenter.org/assets/crs/R40501.pdf (14 de agosto de 2014). 